\title{
Hypoxia-Inducible Factor- $1 \alpha$ Protects Cultured Cortical Neurons from Lipopolysaccharide-Induced Cell Death via Regulation of NR1 Expression
}

\author{
Shiu-Hwa Yeh, ${ }^{1,3}$ Jan-Jong Hung, ${ }^{1,2,3}$ Po-Wu Gean, ${ }^{1,3}$ and Wen-Chang Chang ${ }^{1,2,3}$ \\ ${ }^{1}$ Department of Pharmacology, College of Medicine, ${ }^{2}$ Institute of Biosignal Transduction, College of Bioscience and Biotechnology, and ${ }^{3}$ Center for Gene \\ Regulation and Signal Transduction, National Cheng-Kung University, Tainan 701, Taiwan
}

\begin{abstract}
Inflammation is involved in some neurodegenerative disorders. NMDA glutamate receptors play an important role in neuronal development. Here, we show that NR1 expression in the cerebral cortex and primary neurons of rats was upregulated after lipopolysaccharide (LPS) treatment. This increase in NR1 expression was considered to be strongly associated with hypoxia-inducible factor-1 $\alpha$ (HIF-1 $\alpha)$ activation because the treatment of primary neurons with either echinomycin or small interfering RNA (siRNA) targeting HIF-1 $\alpha$ could block NR1 expression. HIF- $1 \alpha$ could be induced by an increase in the translational efficiency of the cells. After this, it was transported into the nucleus where it bound to the NR1 promoter and regulated the induction of NR1 transcriptional activity by LPS. LPS injection into the prefrontal cortex caused neuronal death, and this condition was aggravated by intracerebroventricular injection of echinomycin. Furthermore, knockdown of HIF- $1 \alpha$ and NR1 by the appropriate siRNAs reduced the neurite outgrowth and viability of the primary neurons. These results suggest that NR1 expression is regulated by HIF- $1 \alpha$ and plays a protective role in neurons during LPS challenge.
\end{abstract}

Key words: LPS; HIF-1; NR1; echinomycin; rpS6; cultured cortical neurons

\section{Introduction}

Inflammatory responses may play pathogenic roles in many neurodegenerative diseases. Lipopolysaccharide (LPS), which is present in the outer layer of the cell wall in Gram-negative bacteria, induce innate immune responses via Toll-like receptor 4 (TLR-4) and are recognized by monocytes/macrophages. In the CNS, LPS-induced chronic inflammation in the rat brain leads to the degeneration of hippocampal CA3 pyramidal neurons and impairs spatial memory (Hauss-Wegrzyniak et al., 1998). Thus, the symptoms induced by inflammation are considerably similar to those of Alzheimer's disease in animal models.

The NMDA glutamate receptor (NMDAR) is a tetramer formed by interaction between an obligatory NR1 subunit and NR2A-NR2D (Monyer et al., 1994; Laube et al., 1998; Mcllhinney et al., 1998). NR1 expression is regulated by physiological conditions in the CNS, including those associated with neuronal plasticity, learning, and memory (Alvarez et al., 2007; Simões et al., 2007). However, inappropriate NMDAR activation is involved in the etiology of several human diseases, including acute insults such as hypoxia (Machaalani and Waters, 2002), ischemia

\footnotetext{
Received Sept. 6, 2008; revised Nov. 11, 2008; accepted Nov. 12, 2008.

This work was supported by the National Cheng Kung University project of the Program for Promoting Academic Excellence and Developing World Class Research Centers, together with Grant NSC 97-2311-B-006-002-MY3 obtained from the National Science Council, Republic of China.

Correspondence should be addressed to either of the following: Jan-Jong Hung, Institute of Biosignal Transduction, College of Bioscience and Biotechnology, National Cheng-Kung University, Tainan 701, Taiwan, E-mail: petehung@mail.ncku.edu.tw; or Wen-Chang Chang, Department of Pharmacology, College of Medicine, National Cheng-Kung University, Tainan 701, Taiwan, E-mail: wcchang@mail.ncku.edu.tw. DOI:10.1523/JNEUROSCI.4258-08.2008

Copyright $\odot 2008$ Society for Neuroscience $\quad 0270-6474 / 08 / 2814259-12 \$ 15.00 / 0$
}

(Cui et al., 2007), trauma (Wang et al., 2005), epilepsy (Toro et al., 2007), and in the pathology of various chronic neurodegenerative diseases such as Alzheimer's disease, Parkinson's disease, Huntington's disease, and amyotrophic lateral sclerosis (Choi, 1988; Lipton and Gendelman, 1995; Kaul et al., 2001; Mattson, 2004). The development of neuronal injuries mediated by HIV-1 infection or LPS infusion can be arrested by treatment with the NMDAR antagonist MK801 [(+)-5-methyl-10,11-dihydro-5Hdibenzo[a,d]cyclohepten-5,10-imine hydrogen maleate] or memantine (Zheng et al., 2001; Glezer et al., 2003; Kowal et al., 2004). Although accumulated evidence indicates that NR1 expression is altered during neuroinflammation (Poon et al., 2006; Q. Zhou et al., 2006), the precise role played by NR1 in neuroinflammation remains unknown.

Hypoxia-inducible factor (HIF), which is a key mediator of oxygen homeostasis, is a dimeric transcriptional complex composed of an oxygen-regulated subunit, HIF- $1 \alpha$, and a constitutively expressed subunit, HIF- $1 \beta$. Under normoxic conditions, the proline 402 and 564 residues in HIF- $1 \alpha$ are hydroxylated by $\mathrm{O}_{2}$-dependent proline hydroxylases, after which they undergo ubiquitination and proteasomal degradation. In hypoxia, when proline hydroxylases are not active, HIF- $1 \alpha$ accumulates and binds to HIF- $1 \beta$, thus forming a heterodimer. This heterodimer plays a role in the transcription regulation of hypoxia-inducible genes involved in angiogenesis, glucose transport and metabolism, erythropoiesis, inflammation, apoptosis, and cellular stress (Zarember and Malech, 2005). Furthermore, recent studies indicate that LPS-stimulated macrophages release nitric oxide (NO) and tumor necrosis factor- $\alpha$ (TNF- $\alpha$ ) via HIF- $1 \alpha$ stabilization 
under normoxic conditions (Zhou et al., 2003). In neuronal cells, LPS-induced inflammation causes neuronal loss and impaired memory (Hauss-Wegrzyniak et al., 1998; Monje et al., 2003). Recent studies have indicated that TLR-3 or TLR- 4 is expressed in neurons (Maœliñska et al., 2004; Wadachi and Hargreaves, 2006); however, the detailed processes regulated by these receptors remain unknown. In this study, the prefrontal cortex in rats and cultured cortical neurons were treated with LPS to assess the relationship between neuroinflammation and NR1 expression. We found that LPS selectively induces NR1 expression in neurons via HIF- $1 \alpha$ activation and that NR1 downregulation by small interfering RNA (siRNA) targeting HIF-1 $\alpha$ or echinomycin treatment increases neuronal damage after LPS treatment.

\section{Materials and Methods}

Experimental animals. Male Sprague Dawley rats weighing 280-320 g were used. They were housed in group cages of two or three rats each in an air-conditioned vivarium with ad libitum access to food and water. Throughout the study, a $12 \mathrm{~h}$ light/dark cycle was maintained with lights on at 8:00 A.M. All procedures adhered to the Guidelines for Care and Use of Experimental Animals of the National Cheng-Kung University. For surgical preparation, rats were anesthetized (intraperitoneally) with $10 \%$ chloral hydrate. Injection of LPS ( $2 \mu \mathrm{g}$ in $5 \mu \mathrm{l}$ of saline) from Escherichia coli 0111:B4 (Sigma-Aldrich) into prefrontal cortex was made $3.2 \mathrm{~mm}$ anterior, $1.3 \mathrm{~mm}$ lateral, and $3.5 \mathrm{~mm}$ ventral from the bregma, according to a stereotaxic atlas. Administration of echinomycin $(1 \mu \mathrm{g}$ in $5 \mu \mathrm{l}$ of saline; Sigma-Aldrich) into lateral ventricular was made $0.4 \mathrm{~mm}$ posterior, $1.3 \mathrm{~mm}$ lateral, and $3.5 \mathrm{~mm}$ ventral from the bregma (Macrae et al., 1993; Sharkey et al., 1993). Drug was administered to the cortex in a volume of $5 \mu \mathrm{l}$ at a rate of $0.1 \mu \mathrm{l} / \mathrm{min}$. It has been confirmed that sham control with inserted cannula plus vehicle had no significant injury to the tissue. To verify the site of the lesions, brains were removed and fixed in formalin, and sections were stained with hematoxylin and eosin. Rats in which lesions did not fit the above criteria were excluded from the study.

Culture of cortical neurons and mixed glial cells. Rat cortical neurons were cultured from postnatal day 0 ( $\mathrm{P} 0)$ to $\mathrm{P} 1$ rat pups. The cortex was dissected and digested in $7 \mathrm{ml}$ of trypsin $(10 \mathrm{U} / \mathrm{ml})$ in PBS at $37^{\circ} \mathrm{C}$ for 30 $\min$. After rinsing, the tissue was triturated and filtered through a nylon mesh filter ( $70 \mu \mathrm{m}$; Small Parts). Cells were plated at a density of $0.5 \times$ $10^{6} \mathrm{cells} / \mathrm{cm}^{2}$ onto a plastic culture plate that was precoated with polyL-lysine ( $50 \mu \mathrm{g} / \mathrm{ml}$; Sigma-Aldrich) and maintained in the Neurobasal A medium supplemented with $100 \mathrm{U} / \mathrm{ml}$ penicillin, $0.1 \mathrm{mg} / \mathrm{ml}$ streptomycin, $0.5 \mathrm{~mm}$ L-glutamine, and 5\% FBS (Invitrogen). On the next day, $8 \mu \mathrm{M}$ cytosine arabinoside (Ara-C; Invitrogen) was added to prevent glial cell growth. The proportion of glial cell was $<5 \%$ in total population of primary cortical cultured cells (supplemental Fig. 2, available at www. jneurosci.org as supplemental material). For primary mixed glial cultures, cells were plated at $2 \times 10^{5}$ cells $/ \mathrm{cm}^{2}$ onto a plastic culture plate coated with poly-L-lysine. Cultures were maintained in DMEM supplemented with 5\% FBS and $100 \mathrm{U} / \mathrm{ml}$ penicillin. All the cells were kept at $37^{\circ} \mathrm{C}$ in a humidified atmosphere of $5 \% \mathrm{CO}_{2}$ and $95 \%$ air. The proportion of neurons and glial cells in cultured cortical neurons was shown in supplemental Figure 2 (available at www.jneurosci.org as supplemental material).

Construction of plasmids. Cloning of the upstream region of the rat gene, NMDAR1, which encodes the NMDA receptor I [National Center for Biotechnology Information (NCBI) accession no. NM017010] from a rat chromosome has been described previously (Bai and Kusiak, 1995). All truncation at the $5^{\prime}$-end was generated by PCR amplification by the use of Taq polymerase (Peqlab). The sequences of PCR primers used to generate $p$ GL2-NR1-473 and pGL2-NR1-356 constructs and expected product sizes are listed in Table 1. A PCR-based protocol was applied to introduce site-directed mutations into two identified HIF-1 binding elements (HREs) that were located between -405 and -387 bp in the promoter of the NMDAR1 gene. For this purpose, the following PCR primers (Table 1) were used with pGL2-NR1-473 serving as DNA template. The amplified DNA was ligated into the NheI-BglII sites of the
Table 1. PCR primer sequences

\begin{tabular}{|c|c|c|}
\hline Gene name & Primer & Sequence $\left(5^{\prime}-3^{\prime}\right)$ \\
\hline & Sense & 5'-CCCGGGTCAGCTATTGAAGGTCTG-3' (-473/-449) \\
\hline \multirow[t]{2}{*}{ pGL2-NR1-473 } & Antisense & 5'-GAGCTCCGGGCACAGCGGGCCTGG-3' $(-24 / 1)$ \\
\hline & Sense & 5'-CATTCACGCCAACGCAGGCGCGCG-3' $(-356 /-332)$ \\
\hline \multirow[t]{2}{*}{ pGL2-NR1-356 } & Antisense & $5^{\prime}$-GAGCTCCGGGCACAGCGGGCCTGG-3' (-24/1) \\
\hline & Sense & 5'-TGCTAACGCGAAAACACACACCCT-3' (-415/-392) \\
\hline \multirow[t]{2}{*}{ pGL2-NR1-mHRE1 } & Antisense & 5'-AGGGTGTGTGTTTTCGCGTTAGCA-3' (-415/-392) \\
\hline & Sense & $5^{\prime}$-СACACACCCTAAAAGGCGCTCCTC-3' $(-401 /-378)$ \\
\hline \multirow[t]{4}{*}{ pGL2-NR1-mHRE2 } & Antisense & 5'-GAGGAGCGCCTTTTAGGGTGTGTG-3' (-401/-378) \\
\hline & & 5'-TGCTAACGCGAAAACACACACCCTAAAAGGCGCTCCTC-3' \\
\hline & Sense & $(-415 /-378)$ \\
\hline & & 5'-GAGGAGCGCCTTTTAGGGTGTGTGTTTTCGCGTTAGCA-3' \\
\hline \multirow[t]{2}{*}{ pGL2-NR1-mHRE1/2 } & Antisense & $(-415 /-378)$ \\
\hline & Sense & 5'-ATGAGCACCATGCACCTGCTGACA-3' (266/290) \\
\hline \multirow[t]{2}{*}{ pcDNA3.1-NR1-myc/His } & Antisense & 5'-GCTCTCCCTATGACGGGAACACAG-3' (3056/3079) \\
\hline & Sense & 5'-TCAAGTCAGCAACGTGGAAG-3' (577/596) \\
\hline \multirow[t]{2}{*}{ HIF- $1 \alpha$} & Antisense & 5'-TATCGAGGCTGTGTCGACTG-3' (755/774) \\
\hline & Sense & 5'-TGACAACTTTGGCATCGTGGAAGG-3' (565/588) \\
\hline \multirow[t]{2}{*}{ GAPDH } & Antisense & 5'-CAACGGATACATTG GGGGTAGGAAC-3' (774/797) \\
\hline & Sense & 5'-TCCACCAAGAGCCCTTCGTG-3' (1473/1492) \\
\hline NR1 & Antisense & 5'-GGCCCCGTACAGATCACCTT-3' (1562/1681) \\
\hline
\end{tabular}

pGL2basic plasmid yielding pGL2-NR1-mHRE1, pGL2-NR1-mHRE2, and $p$ GL2-NR1-mHRE1/2. The plasmid $p c D N A 3.1-N R 1-m y c / H i s$ was generated by PCR using primer pairs (Table 1) and the amplified sequence was verified. The correct identity of the amplified DNA was assessed by automated sequencing (MWG Biotech).

Western blot analysis. Primary cortical neurons were lysed briefly in homogenizing buffer [1\% Triton X-100, 50 mm Tris-HCl, pH 7.5, 0.3 M sucrose, 5 mM EDTA, 2 mm sodium pyrophosphate, 1 mM sodium orthovanadate, $1 \mathrm{~mm}$ phenylmethylsulfonyl fluoride (PMSF), $20 \mu \mathrm{g} / \mathrm{ml}$ leupeptin, and $4 \mu \mathrm{g} / \mathrm{ml}$ aprotinin]. An equal amount of sample was loaded in each lane. For detection of NR1 and $\alpha$-actin, blots were incubated with antibodies against NR1 (1:2500; Santa Cruz Biotechnology) or $\alpha$-actin (1:5000; Santa Cruz Biotechnology). For detection of HIF- $1 \alpha$ and histone $\mathrm{H} 1$, nuclear extracts were prepared as described, and blots were performed with antibodies against HIF- $1 \alpha$ (1:1000; Novus Biologicals) and histone H1 (1:2500; Sigma-Aldrich), respectively. An enhanced chemiluminescence kit was used for detection. Western blots were developed in the linear range used for densitometry. The density of the immunoblots was determined by an image analysis system installed with BIO-ID software (Vilber Lourmat).

Immunostaining. Briefly, rat brain was fixed in $4 \%$ paraformaldehyde in PBS for $2 \mathrm{~h}$ at $4^{\circ} \mathrm{C}$. The brain section was glued to the chuck of a Vibroslice tissue slicer. Transverse slices of $10 \mu \mathrm{m}$ thickness were cut, and the appropriate slices were placed on a microscope slide. Primary neurons were washed with cold PBS and fixed at room temperature for 20 min with $4 \%$ paraformaldehyde. After washing, slices or cells were incubated with blocking solution containing $0.5 \%$ Triton X-100 and $5 \%$ goat serum in PBS for $1 \mathrm{~h}$, and then incubated with mouse antibody against HIF-1 $\alpha$ (1:200; Novus Biologicals), NeuN (1:50; Millipore Bioscience Research Reagents), or rabbit antibodies against GFAP (1:400; SigmaAldrich), NR1 (1:200; Santa Cruz Biotechnology) overnight. After washing three times with PBS, cells were incubated with Alexa 488-conjugated anti-mouse antibody (1:200; Invitrogen), Alexa 568-conjugated antimouse antibody (1:200; Invitrogen), Alexa 488-conjugated anti-rabbit antibody (1:200; Invitrogen), Alexa 568-conjugated anti-rabbit antibody (1:200; Invitrogen), and 4',6-diamidino-2-phenylindole (DAPI) for $1 \mathrm{~h}$. The cells were washed three times with PBS and mounted with glycerol. For measurement of neurite outgrowth, cells or slices were immunostained with antibody against MAP2 (1:200; Sigma-Aldrich). MAP2stained neurons were randomly selected and dendrite length $(L)$ in a cell culture or slices can be estimated from the equation: $L=(\pi d / 2)^{\star} I$, where $d$ is the vertical distance between two parallel lines and $I$ is the number of intersections between the test lines and the neurites. All im- 
ages were analyzed under a confocal fluorescence microscope (Olympus FluoViewFV 1000).

RNA interference. To suppress the expression of HIF- $1 \alpha$ and NR1, either 20 nм HIF- $1 \alpha$ siRNA (Ambion) or NR1 short hairpin RNA (Institute of Molecular Biology, Academia Sinica, Taipei, Taiwan) was transfected to cortical neurons with Lipofectamine 2000 (Invitrogen). Thirty hours after transfection, neurons were treated with LPS $(10 \mu \mathrm{g} / \mathrm{ml}$; Sigma-Aldrich) for various periods of time. At appropriate times, the cells were lysed and assayed for viability or Western blot analyses as described below.

Reporter assays. Firefly luciferase activity was measured by a luminometer (model TD 20/20; Turner Designs) using the reagents provided from the Dual Luciferase Reporter kit (Promega). The assay was performed following the manufacturer's recommendations. Transfection efficiency was corrected by normalizing the data to the corresponding Renilla luciferase activity for each construct.

Reverse transcription-PCR and real-time PCR analysis. Primary neurons were mixed with $600 \mu \mathrm{l}$ of TRI reagent (Invitrogen) to extract cellular mRNA. Single-strand cDNA was synthesized from the cellular mRNA by adding $1 \mu \mathrm{l}$ of StrataScript reverse transcriptase $(200 \mathrm{U} / \mu \mathrm{l}$; Stratagene), $10 \mu \mathrm{l}$ of buffer ( $250 \mathrm{~mm}$ Tris- $\mathrm{HCl}, 375 \mathrm{~mm} \mathrm{KCl}$, and $15 \mathrm{~mm}$ $\left.\mathrm{MgCl}_{2}\right), 5 \mu \mathrm{l}$ of DTT $(0.1 \mathrm{M}), 1 \mu \mathrm{l}$ of oligo-dT, and $18 \mu \mathrm{l}$ of mixed dNTPs $(2.5 \mathrm{~mm})$. The mixture was incubated for $50 \mathrm{~min}$ at $50^{\circ} \mathrm{C}$. The reaction was terminated by heating the mixture to $70^{\circ} \mathrm{C}$ for $10 \mathrm{~min}$ and then icing. Real-time PCR was performed with a LightCycler (Roche Diagnostics). The primers of HIF- $1 \alpha$, glyceraldehyde-3-phosphate dehydrogenase (GAPDH), and NR1 were shown in Table 1. The reaction mixture (total volume, $10 \mu \mathrm{l}$ ) contained $1 \mu \mathrm{l}$ of LightCycler DNA Master Hybridization Probes reaction mix (Roche Diagnostics), $3 \mathrm{~mm} \mathrm{MgCl}, 2 \mu \mathrm{l}$ of cDNA, $250 \mathrm{~nm}$ each of the two primers, and $125 \mathrm{nmol} / \mu$ l each of the dual-labeled fluorescent probes. The thermal profile used was initiated at $95^{\circ} \mathrm{C}$ for 10 min (preamplification hot start), followed by 50 cycles of PCR at $95^{\circ} \mathrm{C}$ for $10 \mathrm{~s}$ (denaturation), $54^{\circ} \mathrm{C}$ for $15 \mathrm{~s}$ (annealing), and $72^{\circ} \mathrm{C}$ for $12 \mathrm{~s}$ (extension). At the end of each annealing step, the fluorescent signal of each reaction was measured at a wavelength of $530 \mathrm{~nm}$ with the LightCycler fluorimeter.

DNA affinity precipitation assay. Ten picomoles of a biotin-labeled oligonucleotide corresponding to the hypoxic response element of the NR1 gene (5'-TGCTAACGCGCGTGCACACACCCTCGTGGGCGCTCCTC-3') or mutant probe (5'-TGCTAACGCGAAAACACACACCCTAAAAGGCGCTCCTC-3') were incubated with $125 \mu \mathrm{g}$ of streptavidin-conjugated agarose $(10 \mathrm{mg} / \mathrm{ml}$; Sigma-Aldrich) for $20 \mathrm{~min}$ at $25^{\circ} \mathrm{C}$. The biotinylated oligonucleotide bound to the streptavidinconjugated beads was washed twice with Tris-EDTA and once with DNA affinity precipitation assay (DAPA) buffer ( $25 \mathrm{~mm}$ Tris- $\mathrm{HCl}, \mathrm{pH} 7.5,0.2$ mм EDTA, $0.1 \mathrm{M} \mathrm{KCl}, 20 \%$ glycerol, supplemented with $100 \mathrm{~mm}$ DTT, $100 \mathrm{~mm} \mathrm{Na}_{3} \mathrm{VO}_{4}$, and $500 \mathrm{~mm}$ PMSF). Nuclear proteins (40 $\mu \mathrm{g}$ ) were then mixed with the oligonucleotide, and the mixture was incubated on ice for $1 \mathrm{~h}$. The protein-oligonucleotide bead complexes were washed twice with DAPA buffer to remove unbound proteins. Protein-DNA complexes were resuspended in $5 \times$ sample buffer $(20 \%$ glycerol, $0.2 \%$ bromophenol blue, 4\% SDS, $100 \mathrm{~mm}$ Tris-HCl, pH 6.8) and boiled for 5 min to elute bound proteins. Proteins eluted from the oligonucleotide were then subjected to SDS-PAGE, followed by Western blot analysis.

Chromatin immunoprecipitation assay. Cultured cortical neurons were treated with $1 \%$ formaldehyde in PBS for 15 min at room temperature. Samples were pelleted and resuspended in cell lysis buffer (5 mM PIPES, $\mathrm{pH}$ 8.0, $85 \mathrm{~mm} \mathrm{KCl}, 0.5 \% \mathrm{NP}-40$, and protease inhibitors), and then sonicated. Lysates were incubated with salmon sperm DNA/protein A-agarose (Millipore) to remove nonspecific binding. Cleared lysates were then incubated with anti-HIF- $1 \alpha$ antibodies overnight at $4{ }^{\circ} \mathrm{C}$, followed by incubation with salmon sperm DNA/protein A-agarose for another $2 \mathrm{~h}$. The beads were washed four times with immunoprecipitation wash buffer (100 mM Tris-HCl, pH 9.0, $500 \mathrm{~mm} \mathrm{LiCl,} \mathrm{0.1 \%} \mathrm{NP-40,}$ and $1 \%$ deoxycholic acid). The immune complexes were eluted twice with elution buffer. DNA was purified from the immune complex and analyzed by PCR. The primer sequences used for rat NR1 promoter were 5'-GGTGACGAGAAACCCCTGTA- ${ }^{\prime}$ and $5^{\prime}$-GAGTCATGAGCGGGACCTAC- $3^{\prime}$. $\left[{ }^{35} \mathrm{~S}\right]$ Methionine incorporation. At various time points after LPS treatment, cultured cortical neurons with the density of $5 \times 10^{5} \mathrm{cells} / \mathrm{cm}^{2}$ were washed with PBS and incubated in methionine-free DMEM (Invitrogen), but containing $30 \mu \mathrm{Ci} / \mathrm{ml} \mathrm{L}-\left[{ }^{35} \mathrm{~S}\right]$ methionine (PerkinElmer Life and Analytical Sciences) for $30 \mathrm{~min}$.

RNA immunoprecipitation. Cultured cells were treated with $100 \mu \mathrm{g} / \mathrm{ml}$ cycloheximide (Calbiochem) $5 \mathrm{~min}$ before harvesting. Cell pellets were washed with ice-cold PBS, pH 7.4, containing $100 \mu \mathrm{g} / \mathrm{ml}$ cycloheximide, and then lysed in polysome lysis buffer containing $100 \mathrm{~mm} \mathrm{KCl,} 5 \mathrm{~mm}$ $\mathrm{MgCl}_{2}, 10 \mathrm{~mm}$ HEPES, $1 \%$ Triton X-100, 0.5\% sodium deoxycholate, $100 \mathrm{U} / \mathrm{ml}$ RNase inhibitor, $100 \mu \mathrm{g} / \mathrm{ml}$ cycloheximide, and standard protease inhibitors for $2 \mathrm{~min}$ on ice. Nuclei were pelleted by centrifugation at $20,000 \times g$ at $4^{\circ} \mathrm{C}$ for $5 \mathrm{~min}$. Protein concentration in the soluble fraction was then measured by a Bradford assay, using bovine serum albumin as the standard. One milligram of protein of the supernatant was incubated with $6 \mu \mathrm{g}$ of anti-ribosomal protein S6 (rpS6) antibodies (Santa Cruz Biotechnology) and $30 \mu \mathrm{l}$ of protein $\mathrm{G}$-agarose (Sigma-Aldrich) for $2 \mathrm{~h}$ at $4^{\circ} \mathrm{C}$. After washing four times with polysome lysis buffer, HIF- $1 \alpha$ mRNA bound with the pellets was determined using reverse transcription (RT)-PCR.

Methanethiosulfonate assay. Primary cortical neurons were plated in $6 \times 10^{5}$ cells $/ \mathrm{cm}^{2}$ in 24 -well plates $2 \mathrm{~d}$ before treatment. After treatment with siRNA transfection for $24 \mathrm{~h}$, neurons were treated with LPS for $12 \mathrm{~h}$, and then $20 \mu \mathrm{l}$ of methanethiosulfonate (MTS) $(5 \mathrm{mg} / \mathrm{ml})$ was added to each well, followed by incubation for an additional $30 \mathrm{~min}$. The media was collected and the absorbance measured at $510 \mathrm{~nm}$ using a Rainbow Spectra ELISA microplate reader (Tecan). Cell viability was defined relative to corresponding control cells (i.e., relative cell viability $=$ absorbance of treated sample/absorbance of control sample ${ }^{\star} 100 \%$ ).

Quantification of cell number and volume. To measure the volume of the injury area in the prefrontal cortex, an equation was used: $V=$ $t a(p) \Sigma p$, where $V$ is the total volume of the structure, $t$ is average slice thickness, $\Sigma p$ is the area per point, and $(p)$ is the total number of points hitting the structure of interest. To obtain an estimate of the total number of cells in each injury region, $N$ (cell,reg), the Cavalieri estimate (Gundersen and Jensen, 1987) of the regional prefrontal cortex reference volume, $V($ reg), was multiplied by the regional numerical density, $N V$ (cell/ reg): $N($ cell,reg $)=\Sigma Q^{-} / \Sigma v($ dis $){ }^{*} V($ reg $)$, where $\Sigma Q^{-}$is the total number of cells counted in all dissectors in a region, $\Sigma v($ dis $)$ is the total volume of these disectors equal to the area of the counting frame. Cells in the injury area were counted manually in five serial $10-\mu \mathrm{m}$-thick sections, spaced $50 \mu \mathrm{m}$ apart from bregma level 3.1-3.36 mm under high power $(200 \times)$ on Olympus microscope as described previously.

Statistical analysis. All data from three separate experiments were expressed as mean $\pm \mathrm{SD}$. Comparisons among multiple groups were performed using one-way ANOVA with appropriate post hoc tests, whereas comparisons between two groups were achieved using Student's $t$ test (StatView 5.01; SAS Institute). A value of $p \leq 0.05$ was considered statistically significant.

\section{Results}

\section{Effects of LPS on NR1 expression in the rat brain}

LPS $(2 \mu \mathrm{g})$ was injected into the prefrontal cortex in rats and cause classical inflammatory response in brain (supplemental Fig. 1, available at www.jneurosci.org as supplemental material). One day later, the brains were excised, fixed with $4 \%$ paraformaldehyde, and immunostained with anti-NR1 antibodies. The results revealed that NR1 expression was upregulated in the LPStreated group (Fig. 1A). Three days after the LPS treatment, NeuN immunostaining was performed to examine the effects of the endotoxin on neurons in vivo. The extent of injury induced was greater in the LPS-treated group than in the sham controls (Fig. 1A). Next, to determine the NR1 expression pattern in neurons after LPS treatment, cultured cortical neurons were treated with LPS. As shown in Figure $1 B$, LPS treatment upregulated NR1 expression in a time-dependent manner. ANOVA showed a main effect for group $\left(F_{(6,21)}=27.02 ; p<0.0001\right)$, and Newman- 
Keuls post hoc comparison revealed differences between the naive control and the 4,6 , 12 , and $24 \mathrm{~h}$ time points $(p<0.05)$.

\section{LPS-induced NR1 promoter activity} mediated by hypoxia-response elements To determine whether LPS induces NR1 expression via a step involved in transcription, total RNA was extracted from the cultured cortical neurons at various time points after LPS treatment and was analyzed by real-time RT-PCR. The data obtained indicated that the mRNA expression of NR1 increased $2 \mathrm{~h}$ after LPS treatment, and this upregulated level was sustained for at least $12 \mathrm{~h}$ (Fig. 2A). ANOVA showed a main effect for group $\left(F_{(5,18)}=39.51 ; p<0.0001\right)$, and Newman-Keuls post hoc comparison revealed differences between the naive control and the $2 \mathrm{~h}(p<0.05), 4 \mathrm{~h}(p<0.05), 6 \mathrm{~h}(p<$ $0.01)$, and $12 \mathrm{~h}(p<0.01)$ time points. It has been reported that LPS induces HIF- $1 \alpha$ expression in macrophages (Blouin et al., 2004). To identify the ciselement(s) required for NR1 promoter activation after LPS treatment, a computerbased analysis (with the Transfac system) of the NR1 promoter sequence (NCBI accession no. NM017010) was performed. The results revealed the presence of two HREs that were putative HIF transcription factor-binding sites; these elements contained the core sequence 5'-RCGTG-3' and were designated as HRE1 and HRE2. Furthermore, they were located between -473 and -356 bp upstream from the translation start site of the NR1 gene. To determine the role of these two binding sites in NR1 expression, reporter constructs driven by the NR1 promoter (i.e., the -473 to -356 bp region) were used to determine the transcriptional activity of NR1 in cortical neurons in the absence or presence of LPS. As shown in Figure $2 B$, LPS treatment induced a significant increase in the reporter activity of pGL2NR1-473 ( $p<0.05$, Student's $t$ test) but not in the transcriptional activity of pGL2NR1-356 ( $p>0.05$, Student's $t$ test). In addition, HIF-1 $\alpha$ expression was knocked down by using siRNA targeting HIF- $1 \alpha$ to study the reporter activity driven by the NR1 promoter in the presence of LPS (Fig. 2C). The results revealed that the reporter activity was induced by LPS treatment but was completely abolished after HIF- $1 \alpha$ knockdown (Fig. 2C, lane 3). ANOVA showed a main effect for group $\left(F_{(11,24)}=43.8 ; p<\right.$ 0.0001), Newman-Keuls post hoc comparison revealed differences between the naive control and the LPS and LPS plus scrambled siRNA groups $(p<0.05)$. No significant difference was observed between the naive control and HIF- $1 \alpha$ siRNA group, LPS plus HIF- $1 \alpha$ siRNA group, and scrambled siRNA group $(p>0.05)$. Next, we attempted to identify the HRE site responsible for the LPS-induced NR1 expression. Mutations were gen-
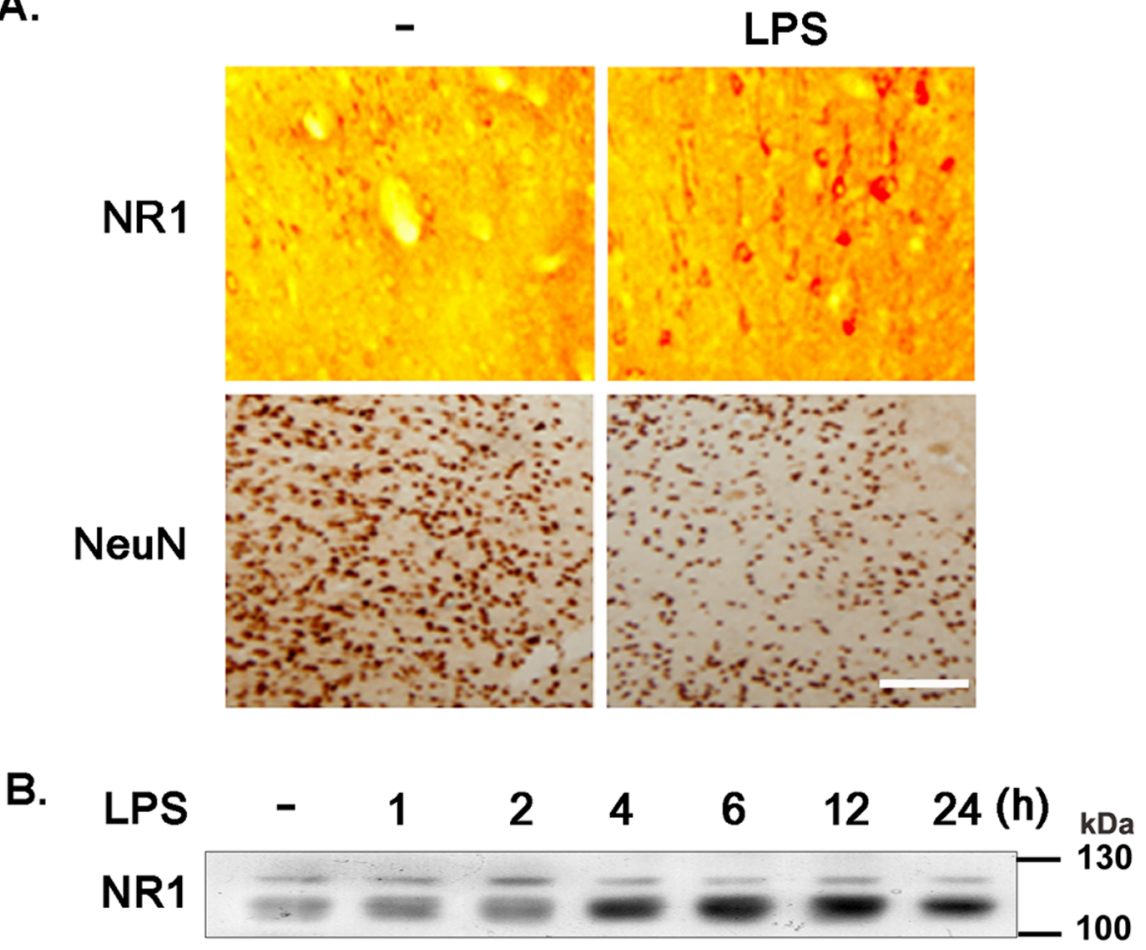

Figure 1. Effects of LPS on NR1 expression in the rat prefrontal cortex. $A$, Saline or LPS $(2 \mu \mathrm{g})$ was injected into the prefrontal cortex in rats. Brain sections were obtained $1 \mathrm{~d}$ later and immunostained with anti-NR1 antibodies, whereas brain sections obtained $3 \mathrm{~d}$ later were immunostained anti-NeuN antibody. Scale bar, $100 \mu \mathrm{m}$. B, Total lysates of the primary neurons were obtained at various time points after LPS treatment. NR1 expression was detected by performing Western blotting with anti-NR1 antibodies, using actin as an internal control. The NR1 expression levels were quantified in three independent experiments and were expressed as a percentage of the levels in the naive controls. Statistical analysis was performed using the one-way ANOVA with appropriate post hoc tests: ${ }^{*} p<0.05$ versus the naive control group.

erated in either one or both of the HREs that were localized by using the NR1 promoter, and a reporter assay was then performed (Fig. 2D). The results indicated that a mutation in any one HRE (i.e., HRE1 or HRE2) could completely inhibit the LPSinduced promoter activity. Student's $t$ test revealed differences between the naive control and the LPS treatment $(p<0.05)$ in pGL2-NR1-473 groups. No significant difference was observed between the naive control and the mutation with either HRE1 or HRE2 site $(p>0.05)$. This indicated that both HREs identified played an important role in the induction of the NR1 promoter activity by LPS. Next, to determine the involvement of HIF- $1 \alpha$ in endogenous NR1 expression, the HIF- $1 \alpha$ inhibitor echinomycin was injected intracerebroventricularly $1 \mathrm{~h}$ before LPS treatment. 
A.

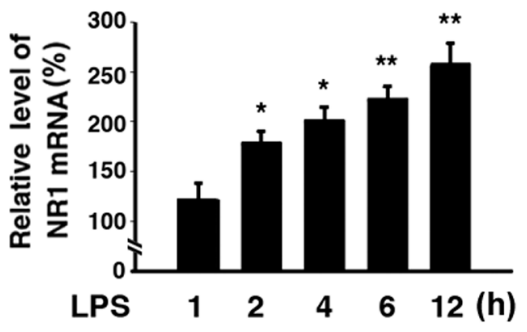

C.

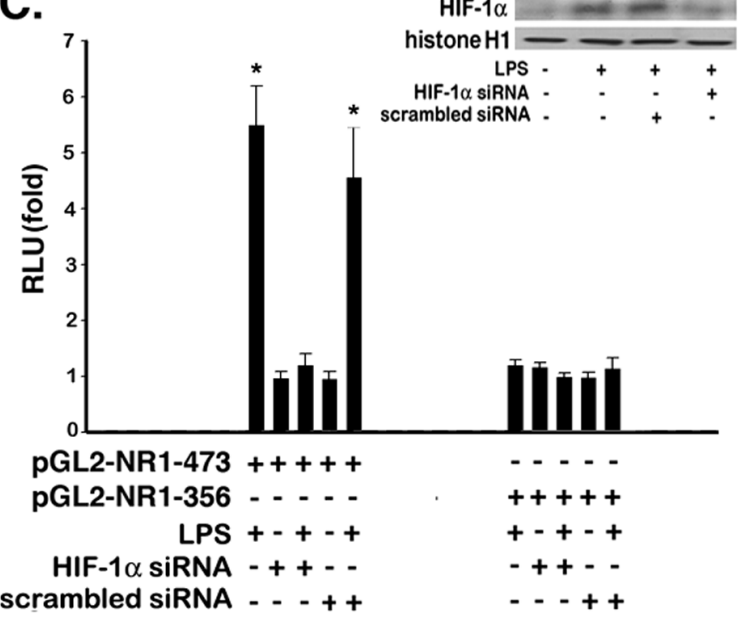

B.

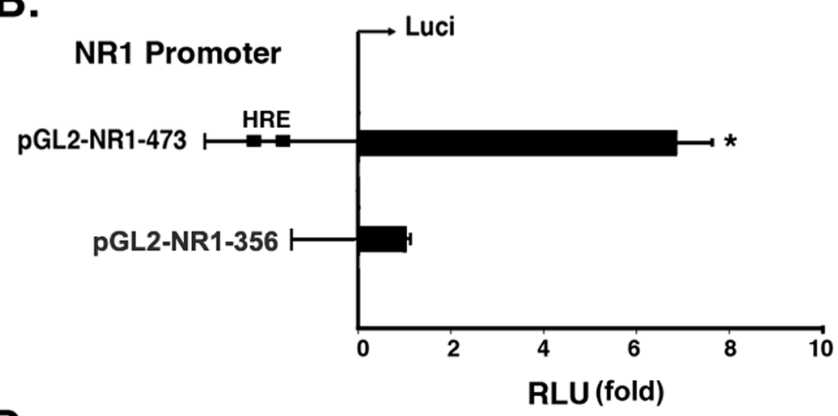

D.

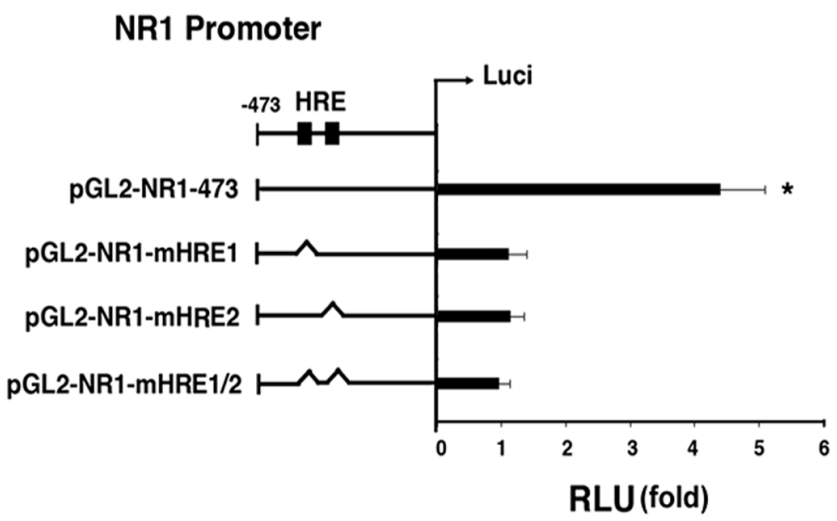

Figure 2. Involvement of HIF-1 $\alpha$ in LPS-induced NR1 expression. $\boldsymbol{A}$, Total RNA was extracted from primary neurons at various time points after LPS treatment. The mRNA expression levels of NR1 were then measured in the total RNA by performing real-time RT-PCR, using GAPDH as an internal control. These levels were expressed as a percentage of those in the naive controls. Statistical analysis was performed using the one-way ANOVA with appropriate post hoc tests: ${ }^{*} p<0.05,{ }^{* *} p<0.05$ versus the naive control group. $\boldsymbol{B}$, To investigate the role of HREs in the LPS-induced transcription activity of NR1, two plasmids (pGL2-NR1-473 and pGL2-NR1-356) containing and lacking two predicted HREs, respectively, were constructed and transfected into the primary neurons. Statistical analysis was performed using the Student's $t$ test: ${ }^{*} p<0.05$ versus the naive control group. C, The pGL2-NR1-473 and pGL2-NR1-356 plasmids were transfected into primary neurons that had been pretransfected with HIF-1 $\alpha$ siRNA and those that had not been pretransfected, respectively. A luciferase assay was then performed, wherein the luciferase activity was determined in the absence or presence of LPS. The efficiency of siRNA-mediated HIF-1 $\alpha$ silencing was determined by performing Western blotting. Statistical analysis was performed using the one-way ANOVA with appropriate post hoc tests: ${ }^{*} p<0.05$ versus the naive control group. D, The pGL2-NR1-473 plasmid and its mutants, namely, pGL2-NR1-mHRE1, pGL2-NR1-mHRE2, and pGL2-NR1-mHRE1/2, were transfected into the primary neurons. At $30 \mathrm{~h}$ after transfection, the neurons were treated with LPS for $16 \mathrm{~h}$, and the luciferase activity was measured. Statistical analysis was performed using the Student's $t$ test: ${ }^{*} p<0.05$ versus the naive control group. $\boldsymbol{B}-\boldsymbol{D}$ show the relative luciferase activity levels expressed as a fold of the corresponding levels in the plasmid-transfected controls. The values represent the means \pm SD recorded during three independent experiments.

As shown in Figure 3Aa, LPS-induced NR1 expression was completely blocked by pretreatment with echinomycin $\left(F_{(3,8)}=\right.$ 5.134; $p<0.05)$. Newman-Keuls post hoc comparison revealed differences between the sham-control and the LPS group $(p<$ 0.05). No significant difference was observed between the sham control and echinomycin group and LPS plus echinomycin group $(p>0.05)$. Furthermore, the effects of echinomycin on brain injury were investigated. As shown in Figure $3 A b$, the length of neurite reduced after echinomycin pretreatment in the presence of LPS $\left(F_{(3,508)}=30.92 ; p<0.0001\right)$. Newman-Keuls post hoc comparison revealed differences between the sham control and the LPS and the LPS plus echinomycin group $(p<0.05)$. No significant difference was observed between the sham control and echinomycin group $(p>0.05)$. The similar result was also observed in the loss of NeuN-positive neurons $\left(F_{(3,8)}=7.621 ; p<\right.$ 0.01 ) (Fig. 3Ac). To determine the effects of HIF-1 $\alpha$ on the neuronal expression of NR1, primary neurons were pretreated with $0.5 \mu \mathrm{M}$ echinomycin for $1 \mathrm{~h}$ before LPS treatment. Total lysates of the neurons were obtained at $6 \mathrm{~h}$ after the LPS treatment and were analyzed by immunoblotting with anti-NR1 antibodies. The results revealed that echinomycin completely blocked the LPSinduced upregulation of NR1 expression (Fig. 3B). ANOVA showed a main effect for group $\left(F_{(3,8)}=35.71 ; p<0.0001\right)$, and
Newman-Keuls post hoc comparison revealed differences between the naive control and the LPS $(p<0.05)$ group. No significant difference was observed between the naive control and echinomycin group and LPS plus echinomycin group $(p>0.05)$. Identical results were obtained in the case of primary neurons that were transfected with siRNA targeting HIF- $1 \alpha 30 \mathrm{~h}$ before LPS treatment. The results revealed that pretreatment with this siRNA blocked the upregulation of NR1 mRNA expression $\left(F_{(5,12)}=20.47\right.$; $p<0.0001$ ) (Fig. 3C). Newman-Keuls post hoc comparison revealed differences between the naive control and the LPS and the LPS plus scrambled siRNA groups $(p<0.05)$. No significant difference was observed between the naive control and HIF- $1 \alpha$ siRNA group, LPS plus HIF- $1 \alpha$ siRNA group, and scrambled siRNA group ( $p>0.05)$. The similar result was observed in the NR1 protein expression in the cultured cortical neurons $\left(F_{(6,14)}=9.313 ; p<0.001\right)$ (Fig. $\left.3 D\right)$. These results demonstrated that LPS-induced NR1 expression is regulated in a HIF-1-dependant manner.

\section{Effects of LPS on HIF-1 $\alpha$ DNA-binding activity}

A DAPA was performed to determine whether HIF- $1 \alpha$ would bind to the identified HREs in the NR1 promoter in vitro. Nuclear extracts of the cultured cortical neurons were prepared at $2 \mathrm{~h}$ after LPS treatment and were incubated with a biotin-labeled oligonu- 


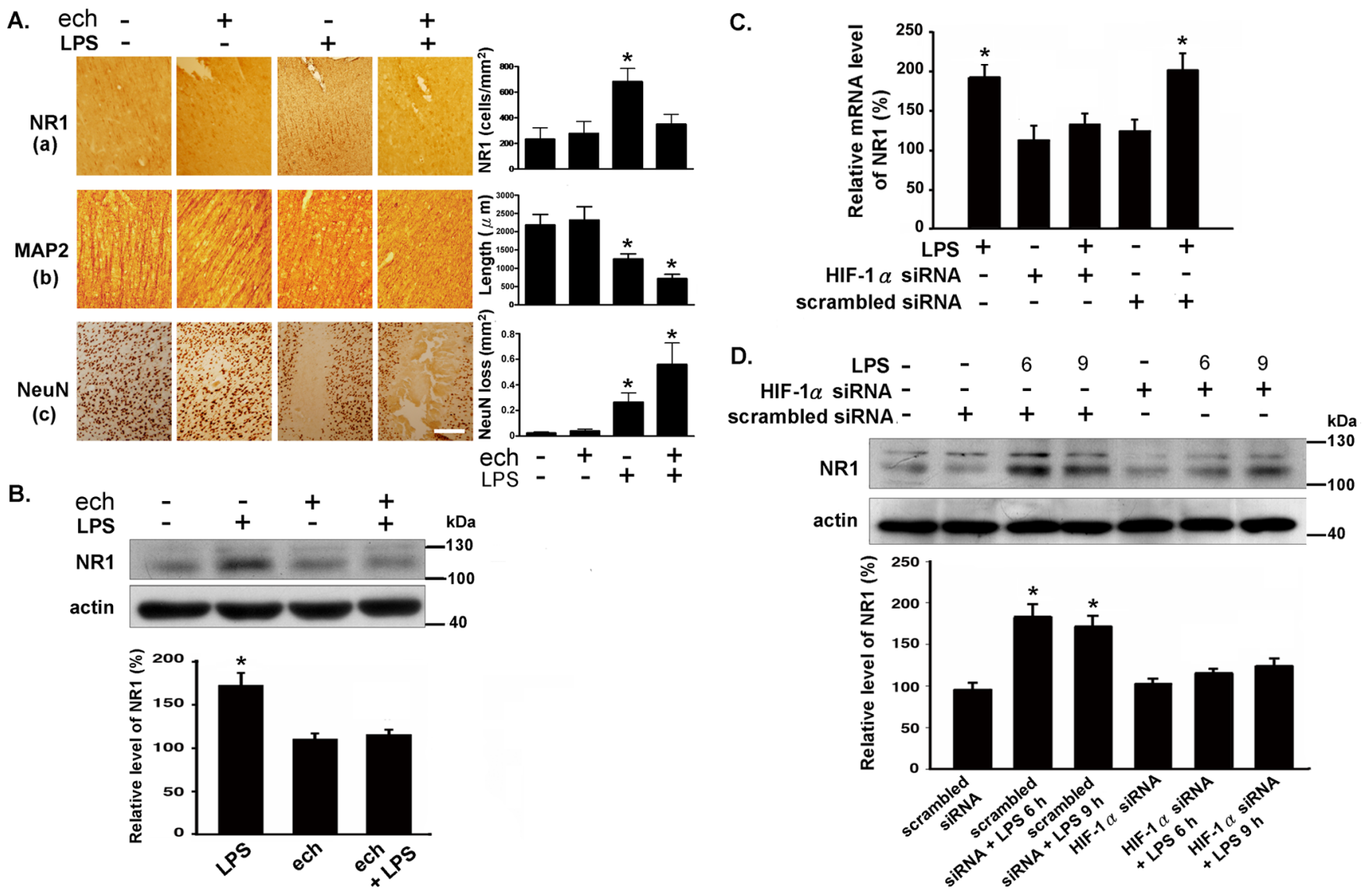

Figure 3. Effects of HIF-1 $\alpha$ on NR1 expression. A, Rats were intracerebroventricularly injected with echinomycin, LPS, or LPS plus echinomycin; $1 \mathrm{~d}$ after the injection, brain sections were obtained and immunostained with anti-NR1 antibodies, whereas $3 \mathrm{~d}$ after the treatment, brain sections were immunostained with anti-NeuN or anti-MAP2 antibody. Quantification of NR1-, MAP2-, and NeuN-positive cells is presented as mean \pm SD. Statistical analysis was performed using the one-way ANOVA with appropriate post hoc tests: ${ }^{*} p<0.05$ versus the naive control group. Scale bar, $100 \mu \mathrm{m} . \boldsymbol{B}$, The cultured cortical neurons were pretreated with $0.5 \mu \mathrm{m}$ echinomycin $1 \mathrm{~h}$ before LPS treatment. Furthermore, $6 \mathrm{~h}$ after the treatment, the cells were harvested, and immunoblotting was performed with anti-NR1 antibodies, using actin as an internal control. The NR1 expression level was quantified in three independent experiments. C, D, siRNA targeting HIF-1 $\alpha$ was transfected into the primary cortical neurons for $30 \mathrm{~h}$, and the cells were then treated with LPS for 6 or $9 \mathrm{~h}$. The mRNA $(\boldsymbol{C})$ and protein $(\boldsymbol{D})$ expression levels of NR1 were analyzed by performing RT-PCR and Western blotting with anti-NR1 antibodies, respectively. The mRNA and protein expression levels of NR1 were quantified in three independent experiments. The values represent the means \pm SD. In $\boldsymbol{B}-\boldsymbol{D}$, statistical analysis was performed using the one-way ANOVA with appropriate post hoc tests: ${ }^{*} p<0.05$ versus the naive control group.

cleotide NR1-HRE1/2 containing the predicted sequences of HRE1 and HRE2. The results revealed that the HIF- $1 \alpha$ DNAbinding activity increased in the nuclear extracts obtained from the primary neurons after LPS treatment (Fig. $4 A$ ). In contrast, the binding activity was lost when the nuclear extracts were incubated with the mutant oligonucleotides (NR1-mHRE1/2). Chromatin immunoprecipitation (ChIP) analysis was then performed to determine whether HIF- $1 \alpha$ interacts with the NR1 promoter in vivo. Compared with the naive controls, the binding of HIF- $1 \alpha$ to the NR1 promoter was detected in the cultured cortical neurons that had been incubated with LPS for at least $2 \mathrm{~h}$ (Fig. $4 B$ ). ANOVA showed a main effect for group $\left(F_{(3,12)}=11.13 ; p<\right.$ 0.001), and Newman-Keuls post hoc comparison revealed differences between the naive control and the 2 and $3 \mathrm{~h}$ time points $(p<0.05)$. This phenomenon was reversed when the primary neurons were pretreated with echinomycin for $1 \mathrm{~h}$ or HIF- $1 \alpha$ siRNA for $30 \mathrm{~h}\left(F_{(4,15)}=14.26\right.$; $\left.p<0.001\right)$ (Fig. $\left.4 C\right)$. NewmanKeuls post hoc comparison revealed differences between the naive control and the LPS and the LPS plus scrambled siRNA groups $(p<0.05)$. No significant difference was observed between the naive control, the LPS plus echinomycin group, and the LPS plus HIF- $1 \alpha$ siRNA group $(p>0.05)$.
LPS-induced HIF-1 $\alpha$ expression under translational control To investigate whether HIF- $1 \alpha$ expression was affected after LPS treatment, we measured this expression in the primary cortical neurons in vitro. The results of the immunostaining (Fig. $5 \mathrm{~A}$ ) revealed that LPS induced the expression of both HIF-1 $\alpha(A a)$ and NR1 $(A b)$ in the primary neurons. In addition, the expression of HIF- $1 \alpha$ and NR1 was colocalized in the same neuron (Fig. $5 A c)$. Furthermore, the results indicated that HIF- $1 \alpha$ was transported from the cytoplasm to the nucleus after LPS treatment (Fig. 5A). To further examine the time-dependent expression of HIF- $1 \alpha$ in the primary neurons, nuclear extracts were prepared at various time points after LPS treatment and were used for immunoblotting analysis. The results indicated that HIF- $1 \alpha$ expression was significantly upregulated in response to LPS treatment (Fig. $5 B)$. ANOVA showed a main effect for group $\left(F_{(6,14)}=14.45 ; p<\right.$ $0.0001)$, and Newman-Keuls post hoc comparison revealed differences between the naive control and the $2 \mathrm{~h}(p<0.01)$ and $4 \mathrm{~h}$ $(p<0.05)$ time points. LPS treatment did not alter the expression level of HIF- $1 \alpha$ in the glial cells $\left(F_{(5,12)}=0.4538 ; p>0.05\right)$ (Fig. $5 C$ ); this indicated that the LPS-induced upregulation of HIF- $1 \alpha$ expression was restricted to the neurons. Furthermore, to elucidate the mechanism by which LPS upregulated HIF- $1 \alpha$ 
A.

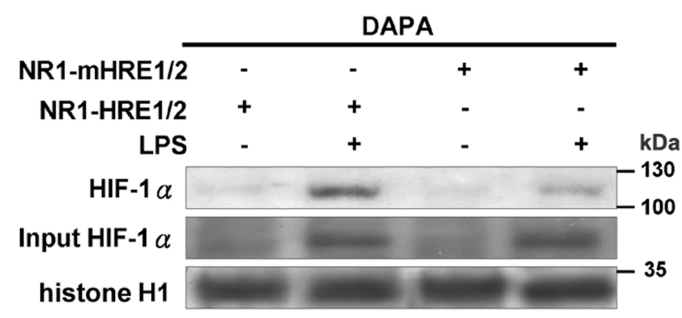

B.

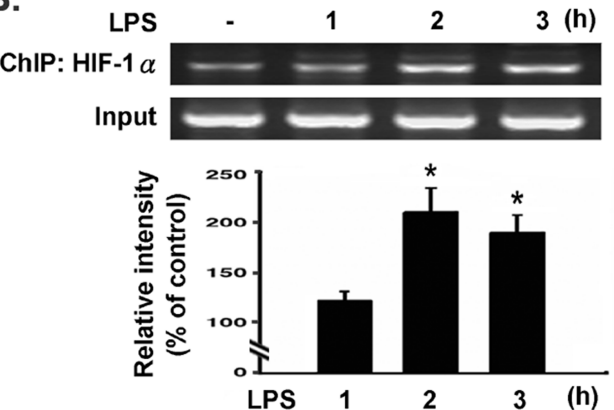

C.
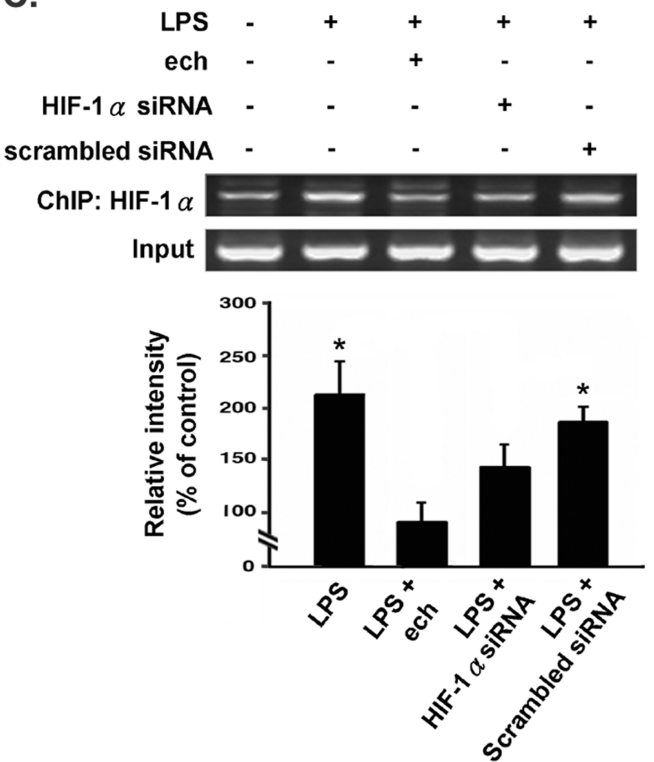

Figure 4. Binding of $\mathrm{HIF}-1 \alpha$ to the NR1 promoter after LPS treatment. $A$, Primary neurons were either treated with LPS or left untreated. Nuclear extracts of the cells were then prepared for the DAPA. The probes used for the DAPA were the sequence 5'-TGCTAACGCGCGTGCACACACCCTCGTGGGCGCTCCTC-3', which was localized within the NR1 promoter, and its mutant probe, $5^{\prime}$ TGCTAACGCGAAAACACACACCCTAAAAGGCGCTCCTC-3'. The DAPA samples were analyzed by performing immunoblotting with the anti-HIF-1 $\alpha$ antibodies. The levels of input HIF-1 $\alpha$ and histone H1 were used as internal controls. $\boldsymbol{B}$, The primary neurons were treated with LPS and were then fixed for the ChIP assay that was performed with anti-HIF- $1 \alpha$ antibodies. The samples for the ChIP assay were analyzed by performing real-time PCR. C, Primary neurons were transfected with either HIF- $1 \alpha$ siRNA or scrambled siRNA for $30 \mathrm{~h}$, whereas the neurons were pretreated with echinomycin before LPS treatment. Three hours later, the neurons were fixed and the ChIP assay was performed using antiHIF- $1 \alpha$ antibodies. The immunoprecipitated samples were assayed by real-time PCR. All the experiments were performed independently in triplicate. $\operatorname{In} \boldsymbol{B}$ and $\boldsymbol{C}$, statistical analysis was performed using the one-way ANOVA with appropriate post hoc tests: ${ }^{*} p<0.05$ versus the naive control group.

expression, real-time RT-PCR was performed to measure the mRNA expression of HIF- $1 \alpha$ in the primary neurons. Total mRNA was extracted from the cultured cortical neurons at various time points after LPS treatment. The results revealed that the
mRNA expression of HIF- $1 \alpha$ was not altered by LPS treatment $\left(F_{(3,12)}=1.916 ; p>0.05\right)$ (Fig. $\left.6 A\right)$. Next, we incorporated $\left[{ }^{35} \mathrm{~S}\right]$ methionine into the culture medium to investigate whether HIF- $1 \alpha$ synthesis increased after LPS treatment. We found that the expression of $\left[{ }^{35} \mathrm{~S}\right]$ methionine-labeled HIF- $1 \alpha$ was significantly upregulated after LPS treatment (Fig. 6B). ANOVA showed a main effect for group $\left(F_{(3,8)}=46.42 ; p<0.0001\right)$, and Newman-Keuls post hoc comparison revealed differences between the naive control and the $1 \mathrm{~h}(p<0.01)$ time point. No significant difference was observed between naive control and 1.5 and $2 \mathrm{~h}$ time points ( $p>0.05$ ). The results of RNA immunoprecipitation analysis also revealed that the LPS treatment increased the interaction between rpS6 and HIF- $1 \alpha$ mRNA $\left(F_{(5,12)}=39.08\right.$; $p<0.0001$ ) (Fig. 6C). Newman-Keuls post hoc comparison revealed differences between the naive control and the 1 and $1.5 \mathrm{~h}$ time point $(p<0.01)$. No significant difference was observed between naive control and 0.5 and $2 \mathrm{~h}$ time points $(p>0.05)$. Next, to determine the involvement of protein stability in LPSinduced HIF- $1 \alpha$ expression, the controls or LPS-treated primary neurons were incubated with anisomycin. Nuclear extracts of the cells were prepared at various time points after the anisomycin treatment, and they were analyzed. The results indicated that the degradation rate of HIF- $1 \alpha$ did not differ significantly between the LPS-treated neurons and the control cells (Fig. 6D,E). These results suggested that an increase in protein translation is a major mechanism involved in the induction of HIF- $1 \alpha$ expression by LPS.

\section{NR1 and HIF- $1 \alpha$ protect primary neurons exposed to an endotoxic challenge}

To investigate the role played by NR1 and HIF- $1 \alpha$ in neurite outgrowth, the neurite length of the primary neurons was measured after LPS treatment with and without NR1 or HIF- $1 \alpha$ silencing. As shown in Figure $7 A$, the neurite length decreased significantly after LPS treatment for $24 \mathrm{~h}$. ANOVA showed a main effect for group $\left(F_{(7,1016)}=24.61 ; p<0.0001\right)$, and Newman-Keuls post hoc comparison revealed differences between the naive control and the LPS group, LPS plus HIF- $1 \alpha$ siRNA group, LPS plus NR1 siRNA group, and LPS plus luciferase siRNA group $(p<0.05)$. No significant difference was observed between naive control and HIF- $1 \alpha$ siRNA group, NR1 siRNA group, and luciferase siRNA group $(p>0.05)$. In addition, the knockdown of NR1 or HIF- $1 \alpha$ with NR1 or HIF- $1 \alpha$ siRNA, respectively, further aggravated this reduction in neurite growth $(p<0.05)$ (Fig. $7 A)$. We next investigated the effects of NR1 and HIF- $1 \alpha$ on the viability of the neurons after LPS treatment. Based on the expression levels of NR1 and HIF-1 $\alpha$, which had been knocked down (Fig. $7 B$ ), we investigated the cell viability in the presence or absence of LPS. The results revealed that the viability of the neurons was reduced by LPS treatment. In addition, the viability of neurons was not affected by NR1 and HIF- $1 \alpha$ knockdown in the absence of LPS treatment but was significantly reduced after LPS treatment for $24 \mathrm{~h}\left(F_{(6,14)}=10.72 ; p<0.001\right)$ (Fig. $\left.7 B\right)$. NewmanKeuls post hoc comparison revealed differences between the naive control and the LPS group, LPS plus HIF- $1 \alpha$ siRNA group, LPS plus NR1 siRNA group, and LPS plus luciferase siRNA group $(p<0.05)$. No significant difference was observed between naive control and HIF- $1 \alpha$ siRNA group, NR1 siRNA group, and luciferase siRNA group $(p>0.05)$. To determine the role of NR1 expression in neurons under LPS challenge, NR1-myc was transfected to the cultured cortical neurons $30 \mathrm{~h}$ before LPS treatment. As shown in Figure $7 C$, neurite outgrowth reduced by LPS was reversed by NR1-myc overexpression. ANOVA showed a main 
A.

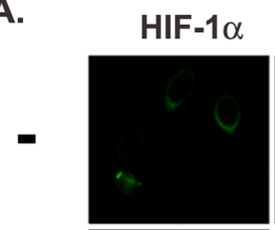

LPS

(2 h)
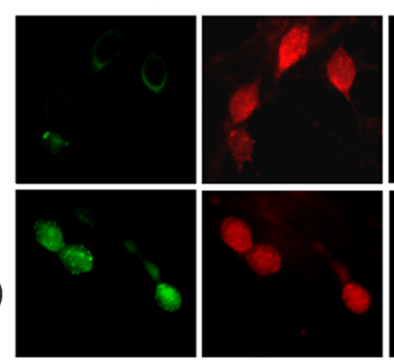

DAPI
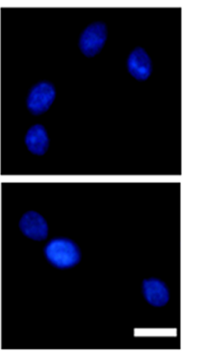

(a)
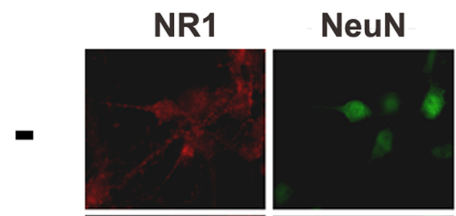

LPS

(6 h)
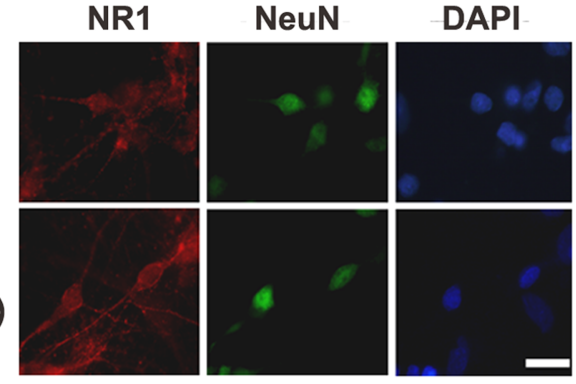

(b)

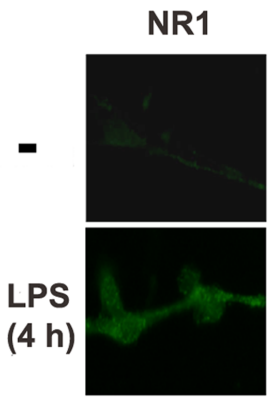

HIF-1 $\alpha$

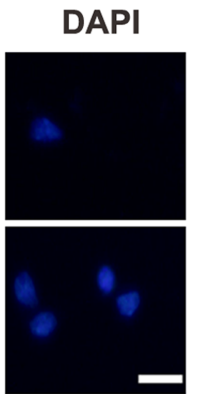

B.

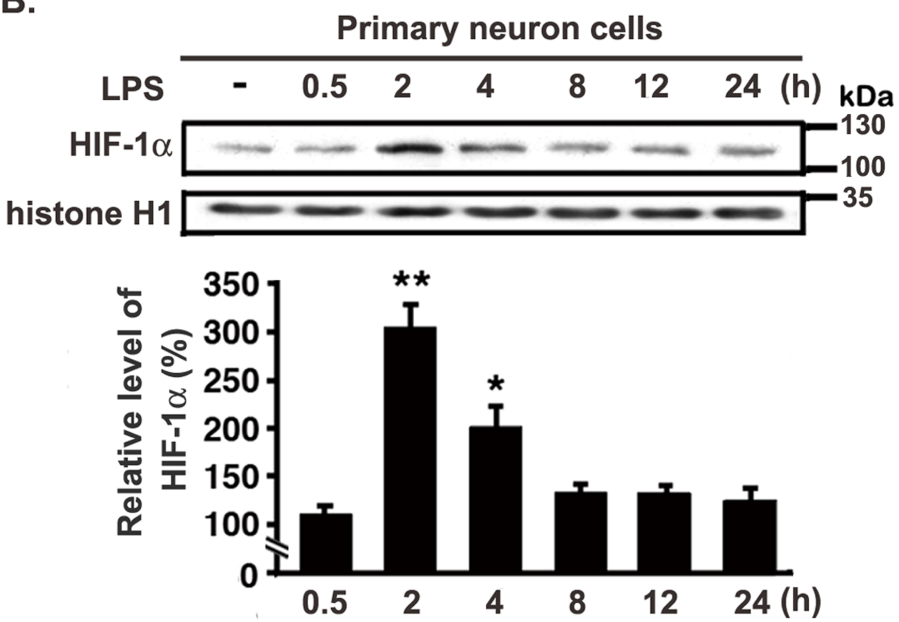

C.
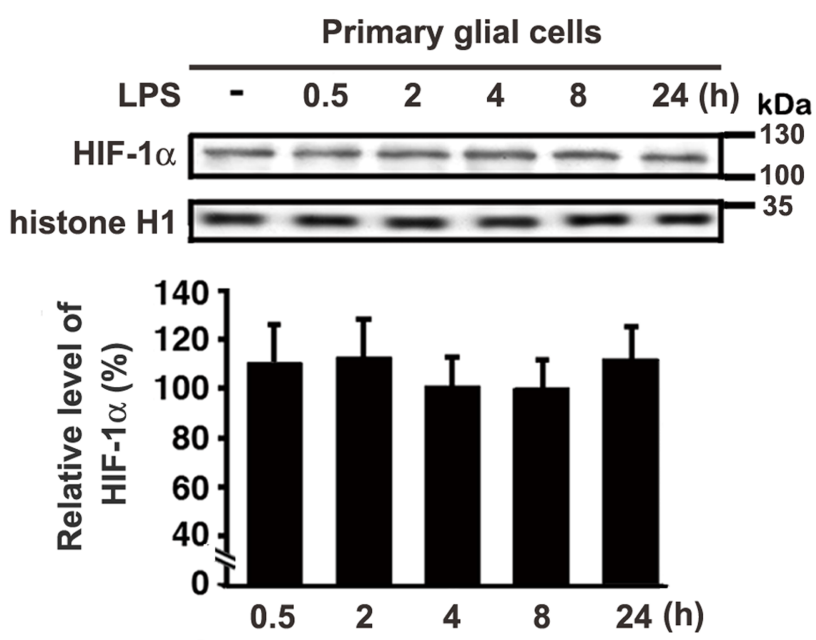

Figure 5. HIF-1 $\alpha$ expression in the neurons after LPS treatment. $A$, At 2, 4, or $6 \mathrm{~h}$ after LPS treatment, the primary neurons were fixed and permeabilized with $1 \%$ Triton X-100 and were subsequently probed with anti-HIF-1 $\alpha$ antibody, anti-NR1 antibodies, and anti-NeuN antibody. HIF-1 $\alpha$ was detected with Alexa 488 (green; $\boldsymbol{a}$ ) or Alexa 568 (red; $\boldsymbol{c}$ ); NR1, with Alexa 568 (red; $\boldsymbol{b}$ ) or Alexa 488 (green; $\boldsymbol{c}$ ); NeuN, with Alexa 568 (red; $\boldsymbol{a}$ ) or Alexa 488 (green; $\boldsymbol{b}$ ). The nucleus was stained with DAPI (blue). Scale bar, $50 \mu \mathrm{m} . \boldsymbol{B}, \boldsymbol{C}$, The time course of HIF-1 $\alpha$ expression induced by LPS treatment in primary neurons or glial cells was assessed. Nuclear extracts of primary neurons $(\boldsymbol{B})$ or glial cells $(\boldsymbol{C})$ were obtained at various time points after LPS treatment. HIF-1 $\alpha$ expression was detected by performing immunoblotting with anti-HIF- $1 \alpha$ antibodies, using histone $\mathrm{H} 1$ as an internal control. All experiments were performed independently in triplicate. Statistical analysis was performed using the one-way ANOVA with appropriate post hoc tests: ${ }^{*} p<0.05,{ }^{* *} p<0.01$ versus the naive control group.

effect for group $\left(F_{(3,508)}=40.86 ; p<0.0001\right)$, and NewmanKeuls post hoc comparison revealed differences between the naive control and the LPS group $(p<0.05)$. No significant difference was observed between naive control and NR1-myc group and LPS plus NR1-myc group ( $p>0.05)$. In addition, the viability of neurons affected by LPS was also rescued by NR1-myc overexpression $\left(F_{(3,8)}=12.77 ; p<0.01\right)$ (Fig. $\left.7 D\right)$. Newman-Keuls post hoc comparison revealed differences between the naive control and the LPS group $(p<0.05)$. No significant difference was observed between naive control and NR1-myc group and LPS plus NR1-myc group ( $p>0.05$ ). Thus, these results suggested that NR1 play a protective role in LPS-treated primary neurons.

\section{Discussion}

LPS, which is an important environmental inducer of inflammation, is associated with many neurodegenerative diseases, including Alzheimer's disease, multiple sclerosis, and amyotrophic lateral sclerosis (Hauss-Wegrzyniak et al., 1998; Gao et al., 2002; Campbell, 2004). Recent studies indicate that both microglial cells and astrocytes are activated during inflammation and release cytokines that cause neuronal damage, including TNF- $\alpha$ (Ledeboer et al., 2002). Minimal knowledge is available regarding neuronal responses to inflammation. Here, we provide evidence that LPS induced the expression of NMDAR subunit 1 in cultured cortical neurons (Fig. $1 B$ ). However, we observed that HIF- $1 \alpha$ inhibition by echinomycin or HIF- $1 \alpha$ knockdown by the appropriate siRNA attenuated NR1 expression (Fig. $3 A-D$ ). Furthermore, LPS induced HIF- $1 \alpha$ expression in cultured cortical neurons but not in primary glial cells (Fig. $5 A-C$ ).

NMDARs play an important role in neuroinflammation. Previous research has revealed that NR1 expression is upregulated during inflammation and plays an important role in maintaining the vasomotor tone in the intermediolateral cell column (IML) during endotoxemia (Poon et al., 2006). However, the mechanism underlying NMDAR expression is unclear. In the present study, evidence obtained in various regards supports the notion that LPS activates the NR1 gene via a mechanism involving HIFs. First, NR1 expression was observed to be upregulated after LPS injection into the prefrontal cortex (Fig. $1 A$ ), and this effect was 
A.

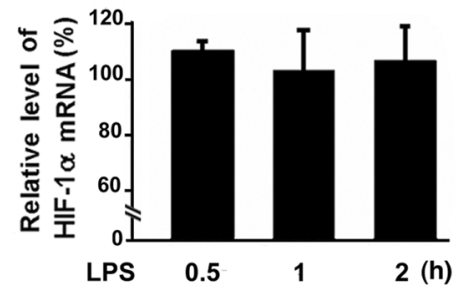

C.

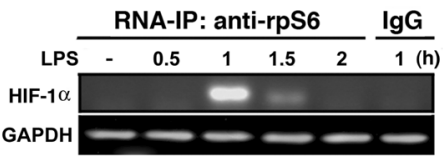

D.

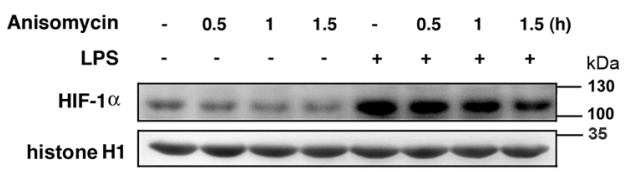

B.
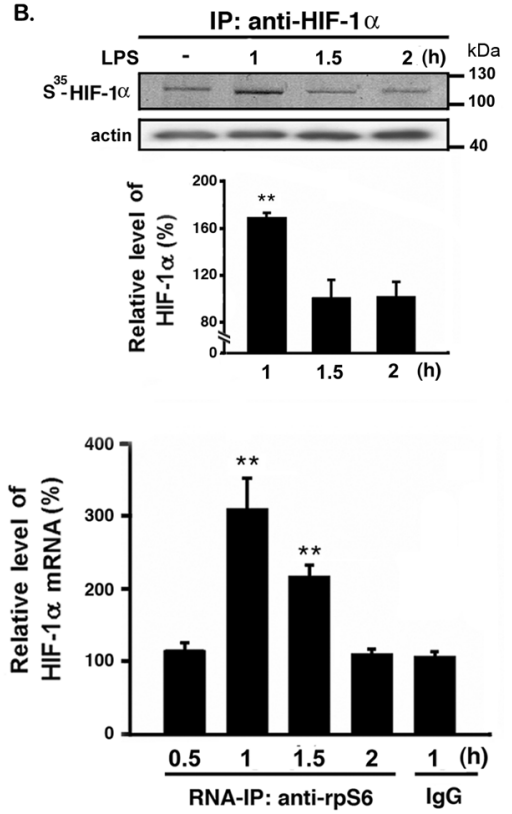

E.

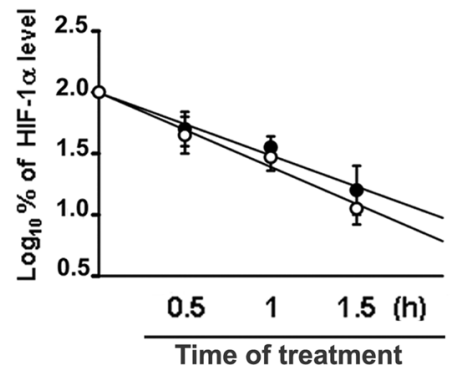

Figure 6. Mechanism underlying the induction of HIF-1 $\alpha$ expression by LPS treatment. $\boldsymbol{A}$, Primary neurons were incubated with LPS, and total RNA was isolated at $0.5,1$, and $2 \mathrm{~h}$ after the treatment. The mRNA expression of HIF- $1 \alpha$ was analyzed by real-time RT-PCR. The results are expressed as arbitrary mRNA units and have been normalized to GAPDH expression. $\boldsymbol{B}$, At various time points after LPS treatment, the neurons were incubated with a medium containing $\left[{ }^{35} S\right]$ methionine for $30 \mathrm{~min}$. The whole-cell lysates were analyzed by immunoprecipitation with anti-HIF- $1 \alpha$ antibodies, followed by autoradiography. C, Wholecell lysates obtained from the primary neurons at each time point after LPS treatment were precipitated with anti-rpS6 antibodies. RNA was extracted from the immunoprecipitated samples, and the HIF- $1 \alpha$ mRNA expression therein was analyzed by RT-PCR. Al experiments were performed independently in triplicate. In $A-C$, statistical analysis was performed using the one-way ANOVA with appropriate post hoc tests: ${ }^{* *} p<0.01$ versus the naive control group. $\boldsymbol{D}$, Primary neurons were treated with anisomycin (10 $\mu \mathrm{m})$ in the absence or presence of LPS (10 $\mu \mathrm{g} / \mathrm{ml})$ and were then harvested with sample buffer after incubation for $0.5,1$, and $1.5 \mathrm{~h}$. The samples were analyzed by immunoblotting with anti-HIF- $1 \alpha$ antibodies, using histone $\mathrm{H} 1$ as an internal control. $\boldsymbol{E}$, Levels of HIF- $1 \alpha$ was plotted on logarithmic scales and lines of best fit were calculated for anisomycin-treated (shaded bar) and anisomycin- plus LPS-treated (open bar) cells. Data in line graphs are averages of four or five separate experiments. Error bars show SD.

blocked by pretreatment with echinomycin (Fig. 3A). Second, experiments performed on cultured cortical neurons indicated that LPS significantly upregulated NR1 expression in these cells (Fig. $1 B$ ), and this effect was attenuated by pretreatment with siRNA targeting HIF- $1 \alpha$ or with echinomycin (Fig. $3 B, D$ ). Third, two predicted HREs that were localized within the NR1 promoter were noted to play an important role in LPS-induced NR1 expression (Fig. $2 B-D$ ). Fourth, the results of the DAPA and ChIP assay revealed that the DNA-binding activity of HIF- $1 \alpha$ toward the two predicted HRE sites in the NR1 promotor increased after LPS treatment (Fig. 4A,B). However, mutation of both these HREs did not further impair the luciferase activity in the assay (Fig. 2D); this may be attributable to these HREs being located too close to each other to independently exert their stimulatory functions (Fig. 2D) (Nakamura et al., 2006). HIFs commonly

interact with HREs containing the core sequence 5'-RCGTG-3' (Semenza et al., 1996; Wenger et al., 2005). However, a single HRE is often insufficient to transmit hypoxia sensitivity signals to a promoter in the absence of adjacent binding sites for transcription factors (Wenger et al., 2005). Remarkably, the $0.5 \mathrm{kbp}$ region located upstream of the NR1 gene contains two consensus HRE sequences that are clustered in active regulatory domains. This supports the idea that the TrkB gene is regulated by HIF- $1 \alpha$ through three HRE sites during hypoxia (Martens et al., 2007). A previous study has reported that $\mathrm{Sp} 1$ stimulates the transcription of the NR1 promoter by binding to a GC-rich consensus motif located in proximity to the HREs identified in the present study (Bai and Kusiak, 1995). Thus, HIF- $1 \alpha$ and Sp1 may function synergistically in regulating NR1 expression.

The phenomenon of NR1 upregulation during inflammation may have major implications with regard to the pathology and the biology of neurons. Previous studies have indicated that NR1 plays a crucial role in maintaining the vasomotor tone in the IML during endotoxemia (Poon et al., 2006). Furthermore, the upregulation of NR1 expression in the spinal cord plays an important role in the development of hyperalgesia after inflammation (Q. Zhou et al., 2006). Inflammation in the prefrontal cortex is strongly associated with Alzheimer's disease (de Pablos et al., 2006). However, it is unclear whether NR1 plays a role in such inflammation. Here, we provide three pieces of evidence supporting the notion that NR1 plays a protective role in local inflammation. First, pretreated echinomycin reduced NR1-, MAP2-, and NeuN-positive neuron expression in the prefrontal cortex after LPS treatment (Fig. $3 A$ ). Second, NR1 silencing exerted a negative effect on neurite growth and increased the cell death after LPS treatment (Fig. $7 A, B$ ). Third, NR1-myc overexpression rescued the viability and neurite growth of neurons from LPS challenge (Fig. 7C,D). However, NR1 was not observed to be involved in neuronal protection and neurite outgrowth in the absence of LPS treatment, which may induce not only NR1 expression but also posttranslational modifications such as phosphorylation that modify its function or other factors affected in the presence of LPS (Caudle et al., 2005). Furthermore, the protective effects of NR1 may be activity dependent because membrane depolarization was required to activate NMDAR (Vissel et al., 2001). In addition, a recent study indicated that NR1 interacts with synaptic adhesion-like molecules (SALMs) and is involved in neurite outgrowth (Wang et al., 2006). It appears that the expressed NR1 interacts with these SALMs in the presence of LPS, and this facilitates the maintenance of the neurite length. Several mechanisms can be proposed for the manner in which NMDARs 
A.
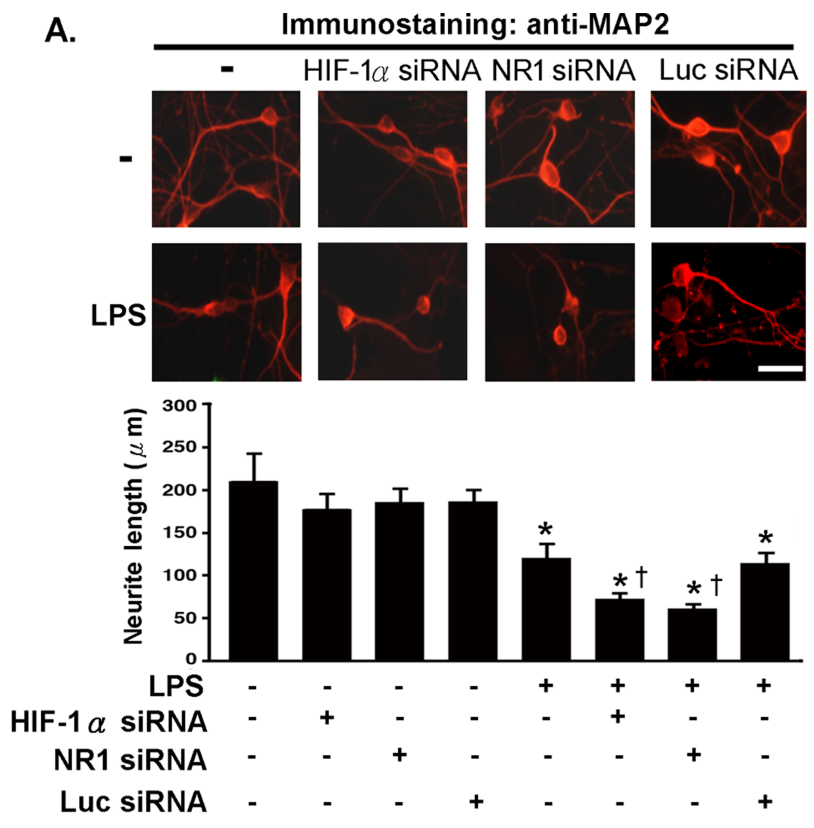

C.

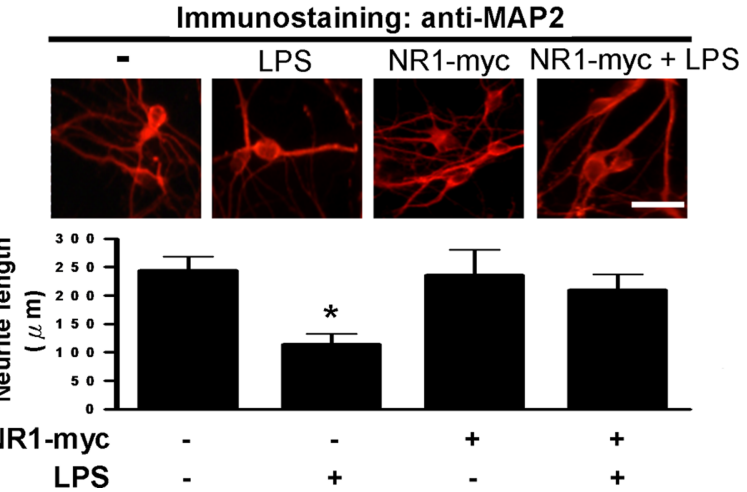

B.
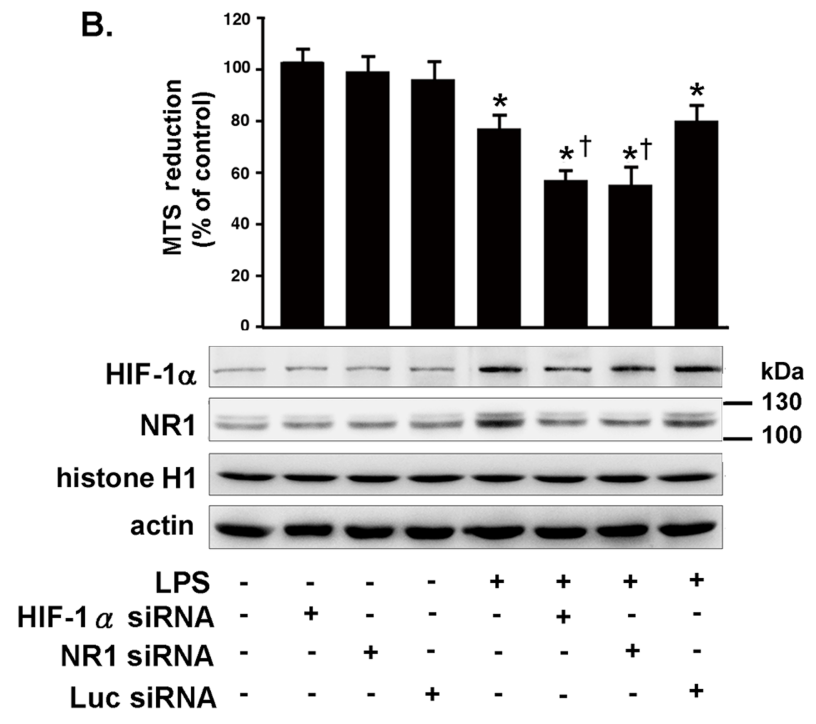

D.

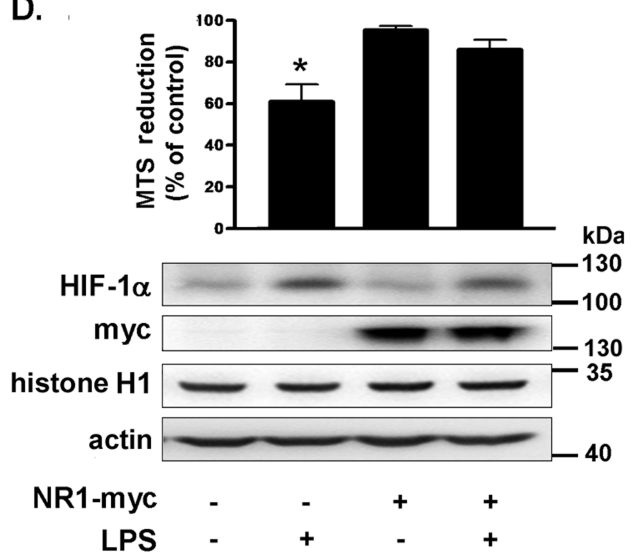

Figure 7. Effects of LPS on neurite length and the viability of primary neurons. A, siRNA targeting HIF- $1 \alpha$ or NR1 was transfected into the neurons $30 \mathrm{~h}$ before LPS treatment. At $24 \mathrm{~h}$ after LPS treatment, the neurons were fixed and immunostained with anti-MAP2 antibody, using Alexa 568 for detection (red). The neurite length was determined for 100 primary neurons under each condition. Scale bar, $50 \mu \mathrm{m}$. B, NR1 or HIF-1 $\alpha$ in LPS-treated or untreated primary neurons was knocked down by using the appropriate siRNA. The viability of the cultured cortical neurons was assessed by performing the MTS assay. The HIF- $1 \alpha$ and NR1 expression levels were used as an internal control for the MTS assay. C, NR1-myc was transfected into the neurons $30 \mathrm{~h}$ before LPS treatment. The neurons were fixed at $24 \mathrm{~h}$ after LPS treatment and immunostained with anti-MAP2 antibody, using Alexa 568 for detection (red). Scale bar, $50 \mu \mathrm{m}$. D, NR1 in LPS-treated or untreated primary neurons was overexpressed by using the NR1-myc. The viability of the cultured cortical neurons was assessed by performing the MTS assay. The HIF-1 $\alpha$ and NR1-myc expression levels were used as an internal control for the MTS assay. In $\boldsymbol{B}$ and $\boldsymbol{D}$, experiments were performed independently in triplicate. The values that were normalized to the protein content are provided as the means $\pm S D(n=3)$ and have been expressed as percentage viability relative to the untreated cells. Statistical analysis was performed using the one-way ANOVA with appropriate post hoc tests: ${ }^{*} p<0.05$ versus the naive control group; ${ }^{\dagger} p<0.01$ versus LPS plus luciferase siRNA group.

protect neurons during LPS treatment. Calcium influx via these receptors can activate various signaling pathways. Accordingly, NMDAR signaling has been found to promote neuron survival during ischemic brain injury and excitatory toxicity via activation of the phosphatidylinositol-3-kinase/Akt pathway (Miao et al., 2005). Furthermore, the activation of NMDA receptor is critical for the expression of NCAM-180, which is important for neuronal growth cone protrusion and neurite extension (Georgiev et al., 2008). It is therefore plausible that the activation of a specific prosurvival mechanism may contribute to the survival of NR1expressing neurons.

HIF- $1 \alpha$ is a transcription factor that functions under stress conditions, especially during hypoxia. Recent studies have investigated the manner in which HIF- $1 \alpha$ is activated by LPS (Peyssonnaux et al., 2007). It has been reported that HIF- $1 \alpha$ expression is primarily regulated by hydroxylation and ubiquitination (Semenza, 2000). Other studies have reported that HIF-1 $\alpha$ ex- pression is regulated by either transcriptional or translational mechanisms. In macrophages and monocytes, mRNA level of HIF- $1 \alpha$ is induced by LPS (Blouin et al., 2004; Frede et al., 2006). In PC12 cells, HIF- $1 \alpha$ translational efficiency is increased during hypoxia (Hui et al., 2006). The results shown here indicate that the protein expression but not the mRNA expression of HIF- $1 \alpha$ was selectively elevated in neurons during LPS treatment (Figs. $5 B, C, 6 A)$. However, the turnover rate of HIF- $1 \alpha$ was not affected by LPS treatment (Fig. $6 D, E$ ), indicating that LPS does not affect its protein stability. Furthermore, the interaction between HIF- $1 \alpha$ mRNA and rpS6 increased and the expression of newly synthesized HIF- $1 \alpha$ was upregulated after LPS treatment (Fig. $6 B, C)$. These findings indicate that HIF- $1 \alpha$ protein synthesis, rather than its mRNA expression, increased significantly after LPS treatment. However, the detailed mechanisms underlying HIF- $1 \alpha$ translation remain unclear. In HEK293 and HeLa cells, hypoxia induces HIF- $1 \alpha$ protein translation through an internal 
ribosome entry site (IRES) element (Lang et al., 2002; Schepens et al., 2005). In contrast, the same conditions induce the capdependent translation of HIF- $1 \alpha$ in PC12 cells (Hui et al., 2006). Based on our novel findings regarding the transient protein expression of HIF- $1 \alpha(\sim 2 \mathrm{~h})$, it is possible that altered activity of the IRES element is related to HIF- $1 \alpha$ expression induced in neurons after LPS treatment.

It was already known that NMDA receptor was composed by NR1 subunit and NR2A-2D subunit or NR3 subunit. Although there was no data about the regulation of NR2 or NR3 expression in the present study, several studies have shown that the composition of NR2A/NR2B was altered in inflammation ( $\mathrm{Wu}$ et al., 2005). Moreover, it was also reported that an acute increase in mRNA level of NR2B-2D rather than NR2A was detected in cortex after intraperitoneal injection of LPS (Harré et al., 2008). Here, we show that NR1 gene expression was induced by LPS both in vivo and in vitro (Fig. $1 A, B$ ). Previous study has been reported that the mRNA level of NR1, NR2A-2D, and NR3 was different in the age of rat. Thus, there is also possibility that the model of the present study was also in age-dependent manner (Harré et al., 2008).

Anisomycin is used to nonspecifically inhibit protein synthesis. In the present experiment to determine protein degradation rate, we treated neurons with anisomycin to investigate whether LPS altered the half-life of HIF- $1 \alpha$. One concern is that anisomycin may cause an undesirable effect on cell viability, rather than just inhibition of protein synthesis. In various previous studies, anisomycin was injected to the brain without causing changes in neuron density, property, morphology, and physiology even with higher concentration (Lin et al., 2003). However, the total processing period in which we treated with anisomycin was only $2 \mathrm{~h}$. Thus, the degradation of HIF- $1 \alpha$ could not be attributable to influence in cell viability.

In summary, the results of the present study revealed that LPS selectively activates HIF- $1 \alpha$ in cortical neurons, whereas HIF- $1 \alpha$ inhibition blocks NR1 expression and decreases the neuron viability. These results represent the first evidence that HIF- $1 \alpha$ activation in neurons is essential during neuroinflammation. Furthermore, the identification of HIF- $1 \alpha$ as a molecular substrate during the development of inflammation provides a more selective and potentially more productive target for the treatment of neurodegenerative diseases.

\section{References}

Alvarez VA, Ridenour DA, Sabatini BL (2007) Distinct structural and ionotropic roles of NMDA receptors in controlling spine and synapse stability. J Neurosci 27:7365-7376.

Bai G, Kusiak JW (1995) Functional analysis of the proximal 5'-flanking region of the $N$-methyl-D-aspartate receptor subunit gene, NMDAR1. J Biol Chem 270:7737-7744.

Blouin CC, Pagé EL, Soucy GM, Richard DE (2004) Hypoxic gene activation by lipopolysaccharide in macrophages: implication of hypoxia-inducible factor 1alpha. Blood 103:1124-1130.

Campbell A (2004) Inflammation, neurodegenerative diseases, and environmental exposures. Ann N Y Acad Sci 1035:117-132.

Caudle RM, Perez FM, Del Valle-Pinero AY, Iadarola MJ (2005) Spinal cord NR1 serine phosphorylation and NR2B subunit suppression following peripheral inflammation. Mol Pain 1:25.

Choi DW (1988) Glutamate neurotoxicity and diseases of the nervous system. Neuron 1:623-634.

Cui H, Hayashi A, Sun HS, Belmares MP, Cobey C, Phan T, Schweizer J, Salter MW, Wang YT, Tasker RA, Garman D, Rabinowitz J, Lu PS, Tymianski M (2007) PDZ protein interactions underlying NMDA receptor-mediated excitotoxicity and neuroprotection by PSD-95 inhibitors. J Neurosci 27:9901-9915.

de Pablos RM, Villarán RF, Argüelles S, Herrera AJ, Venero JL, Ayala A, Cano
J, Machado A (2006) Stress increases vulnerability to inflammation in the rat prefrontal cortex. J Neurosci 26:5709-5719.

Frede S, Stockmann C, Freitag P, Fandrey J (2006) Bacterial lipopolysaccharide induces HIF-1 activation in human monocytes via p44/42 MAPK and NF-kappaB. Biochem J 396:517-527.

Gao HM, Jiang J, Wilson B, Zhang W, Hong JS, Liu B (2002) Microglial activation-mediated delayed and progressive degeneration of rat nigral dopaminergic neurons: relevance to Parkinson's disease. J Neurochem 81:1285-1297.

Georgiev D, Taniura H, Kambe Y, Takarada T, Yoneda Y (2008) A critical importance of polyamine site in NMDA receptors for neurite outgrowth and fasciculation at early stages of P19 neuronal differentiation. Exp Cell Res 314:2603-2617.

Glezer I, Zekki H, Scavone C, Rivest S (2003) Modulation of the innate immune response by NMDA receptors has neuropathological consequences. J Neurosci 23:11094-11103.

Gundersen HJ, Jensen EB (1987) The efficiency of systematic sampling in stereology and its prediction. J Microsc 147:229-263.

Harré EM, Galic MA, Mouihate A, Noorbakhsh F, Pittman QJ (2008) Neonatal inflammation produces selective behavioural deficits and alters $N$-methyl-D-aspartate receptor subunit mRNA in the adult rat brain. Eur J Neurosci 27:644-653.

Hauss-Wegrzyniak B, Dobrzanski P, Stoehr JD, Wenk GL (1998) Chronic neuroinflammation in rats reproduces components of the neurobiology of Alzheimer's disease. Brain Res 780:294-303.

Hui AS, Bauer AL, Striet JB, Schnell PO, Czyzyk-Krzeska MF (2006) Calcium signaling stimulates translation of HIF-alpha during hypoxia. FASEB J 20:466-475.

Kaul M, Garden GA, Lipton SA (2001) Pathways to neuronal injury and apoptosis in HIV-associated dementia. Nature 410:988-994.

Kowal C, DeGiorgio LA, Nakaoka T, Hetherington H, Huerta PT, Diamond B, Volpe BT (2004) Cognition and immunity; antibody impairs memory. Immunity 21:179-188.

Lang KJ, Kappel A, Goodall GJ (2002) Hypoxia-inducible factor-1alpha mRNA contains an internal ribosome entry site that allows efficient translation during normoxia and hypoxia. Mol Biol Cell 13:1792-1801.

Laube B, Kuhse J, Betz H (1998) Evidence for a tetrameric structure of recombinant NMDA receptors. J Neurosci 18:2954-2961.

Ledeboer A, Binnekade R, Brevé JJ, Bol JG, Tilders FJ, Van Dam AM (2002) Site-specific modulation of LPS-induced fever and interleukin-1 beta expression in rats by interleukin-10. Am J Physiol Regul Integr Comp Physiol 282:R1762-R1772.

Lin CH, Yeh SH, Lu HY, Gean PW (2003) The similarities and diversities of signal pathways leading to consolidation of conditioning and consolidation of extinction of fear memory. J Neurosci 23:8310-8317.

Lipton SA, Gendelman HE (1995) Seminars in medicine of the Beth Israel Hospital, Boston. Dementia associated with the acquired immunodeficiency syndrome. N Engl J Med 332:934-940.

Machaalani R, Waters KA (2002) Distribution and quantification of NMDA R1 mRNA and protein in the piglet brainstem and effects of intermittent hypercapnic hypoxia (IHH). Brain Res 951:293-300.

Macrae IM, Robinson MJ, Graham DI, Reid JL, McCulloch J (1993) Endothelin-1-induced reductions in cerebral blood flow: dose dependency, time course, and neuropathological consequences. J Cereb Blood Flow Metab 13:276-284.

Martens LK, Kirschner KM, Warnecke C, Scholz H (2007) Hypoxiainducible factor-1 (HIF-1) is a transcriptional activator of the TrkB neurotrophin receptor gene. J Biol Chem 282:14379-14388.

Maœliñska D, Laure-Kamionowska M, Maœliñski S (2004) Toll-like receptors in rat brains injured by hypoxic-ischaemia or exposed to staphylococcal alpha-toxin. Folia Neuropathol 42:125-132.

Mattson MP (2004) Pathways towards and away from Alzheimer's disease. Nature 430:631-639.

McIlhinney RA, Le Bourdellès B, Molnár E, Tricaud N, Streit P, Whiting PJ (1998) Assembly intracellular targeting and cell surface expression of the human $N$-methyl-D-aspartate receptor subunits NR1a and NR2A in transfected cells. Neuropharmacology 37:1355-1367.

Miao B, Yin XH, Pei DS, Zhang QG, Zhang GY (2005) Neuroprotective effects of preconditioning ischemia on ischemic brain injury through down-regulating activation of JNK1/2 via $N$-methyl-D-aspartate receptor-mediated Akt1 activation. J Biol Chem 280:21693-21699. 
Monje ML, Toda H, Palmer TD (2003) Inflammatory blockade restores adult hippocampal neurogenesis. Science 302:1760-1765.

Monyer H, Burnashev N, Laurie DJ, Sakmann B, Seeburg PH (1994) Developmental and regional expression in the rat brain and functional properties of four NMDA receptors. Neuron 12:529-540.

Nakamura K, Martin KC, Jackson JK, Beppu K, Woo CW, Thiele CJ (2006) Brain-derived neurotrophic factor activation of TrkB induces vascular endothelial growth factor expression via hypoxia-inducible factor-1alpha in neuroblastoma cells. Cancer Res 66:4249-4255.

Peyssonnaux C, Cejudo-Martin P, Doedens A, Zinkernagel AS, Johnson RS, Nizet V (2007) Cutting edge: essential role of hypoxia inducible factor- $1 \alpha$ in development of lipopolysaccharide-induced sepsis. J Immunol 178:7516-7519.

Poon YY, Chang AY, Chan SH (2006) Differential contribution of $\mathrm{N}$-methyl-D-aspartate and non-N-methyl-D-aspartate receptors in the intermediolateral cell column of the thoracic spinal cord to sympathetic vasomotor tone during experimental endotoxemia in the rat. Shock 26:372-378.

Schepens B, Tinton SA, Bruynooghe Y, Beyaert R, Cornelis S (2005) The polypyrimidine tract-binding protein stimulates HIF-1alpha IRESmediated translation during hypoxia. Nucleic Acids Res 33:6884-6894.

Semenza GL (2000) Expression of hypoxia-inducible factor 1: mechanisms and consequences. Biochem Pharmacol 59:47-53.

Semenza GL, Jiang BH, Leung SW, Passantino R, Concordet JP, Maire P, Giallongo A (1996) Hypoxia response elements in the aldolase A, enolase 1, and lactate dehydrogenase A gene promoters contain essential binding sites for hypoxia-inducible factor 1 . J Biol Chem 271:32529-32537.

Sharkey J, Ritchie IM, Kelly PA (1993) Perivascular microapplication of endothelin-1: a new model of focal cerebral ischaemia in the rat. J Cereb Blood Flow Metab 13:865-871.

Simões PF, Silva AP, Pereira FC, Marques E, Grade S, Milhazes N, Borges F, Ribeiro CF, Macedo TR (2007) Methamphetamine induces alterations on hippocampal NMDA and AMPA receptor subunit levels and impairs spatial working memory. Neuroscience 150:433-441.
Toro CT, Hallak JE, Dunham JS, Leite JP, Sakamoto AC, Guarnieri R, Fong V, Deakin JF (2007) The NR1 N-methyl-D-aspartate subunit and brainderived neurotrophic factor in temporal lobe epilepsy hippocampus: a comparison of patients with and without coexisting psychiatric symptoms. Epilepsia 48:2352-2356.

Vissel B, Krupp JJ, Heinemann SF, Westbrook GL (2001) A use-dependent tyrosine dephosphorylation of NMDA receptors is independent of ion flux. Nat Neurosci 4:587-596.

Wadachi R, Hargreaves KM (2006) Trigeminal nociceptors express TLR-4 and CD14: a mechanism for pain due to infection. J Dent Res 85:49-53.

Wang CY, Chang K, Petralia RS, Wang YX, Seabold GK, Wenthold RJ (2006) A novel family of adhesion-like molecules that interacts with the NMDA receptor. J Neurosci 26:2174-2183.

Wang S, Lim G, Zeng Q, Sung B, Yang L, Mao J (2005) Central glucocorticoid receptors modulate the expression and function of spinal NMDA receptors after peripheral nerve injury. J Neurosci 25:488-495.

Wenger RH, Stiehl DP, Camenisch G (2005) Integration of oxygen signaling at the consensus HRE. Sci STKE 2005:1-13.

Wu LJ, Toyoda H, Zhao MG, Lee YS, Tang J, Ko SW, Jia YH, Shum FW, Zerbinatti CV, Bu G, Wei F, Xu TL, Muglia LJ, Chen ZF, Auberson YP, Kaang BK, Zhuo M (2005) Upregulation of forebrain NMDA NR2B receptors contributes to behavioral sensitization after inflammation. J Neurosci 25:11107-11116.

Zarember KA, Malech HL (2005) HIF-1alpha: a master regulator of innate host defenses? J Clin Invest 115:1702-1704.

Zheng J, Thylin MR, Persidsky Y, Williams CE, Cotter RL, Zink W, Ryan L, Ghorpade A, Lewis K, Gendelman HE (2001) HIV-1 infected immune competent mononuclear phagocytes influence the pathways to neuronal demise. Neurotox Res 3:461-484.

Zhou J, Fandrey J, Schümann J, Tiegs G, Brüne B (2003) NO and TNF-alpha released from activated macrophages stabilize HIF-1alpha in resting tubular LLC-PK1 cells. Am J Physiol Cell Physiol 284:C439-C446.

Zhou Q, Caudle RM, Price DD, Del Valle-Pinero AY, Verne GN (2006) Selective up-regulation of NMDA-NR1 receptor expression in myenteric plexus after TNBS induced colitis in rats. Mol Pain 2:3. 